\title{
BREASTFEEDING AND GROWTH IN INFANTS WITH CONGENITAL \\ HEART DISEASE
}

\author{
by
}

Kathryn L. Siemienski

A thesis submitted to the Faculty of the University of Delaware in partial

fulfillment of the requirements for the degree of Master of Science in Human Nutrition

Spring 2019

(C) 2019 Kathryn L. Siemienski

All Rights Reserved 


\title{
BREASTFEEDING AND GROWTH IN INFANTS WITH CONGENITAL HEART DISEASE
}

\author{
by \\ Kathryn L. Siemienski
}

Approved:

Jillian C. Trabulsi, Ph.D, RD

Professor in charge of thesis on behalf of the Advisory Committee

Approved:

P. Michael Peterson, Ed.D.

Chair of the Department of Behavioral Health and Nutrition

Approved:

Kathleen S. Matt, Ph.D.

Dean of the College of Health Sciences

Approved:

Douglas J. Doren, Ph.D.

Interim Vice Provost for Graduate and Professional Education 


\section{ACKNOWLEDGMENTS}

I would like to thank my advisor, Dr. Jillian Trabulsi, for being such a positive influence in my life, both personally and academically. Words cannot describe how thankful I am for the opportunity to have worked together and how much she has taught me. Additionally, I would like to thank my committee members, Rachelle Lessen and Dr. Alisha Rovner, for their guidance and support. I would like to thank another mentor of mine, Dr. Sandra Baker, for providing me with countless opportunities over the past few years that have helped me grow and shaped my career. Lastly, I am truly grateful for the encouragement and support from my family and friends that helped me through this process. 


\section{TABLE OF CONTENTS}

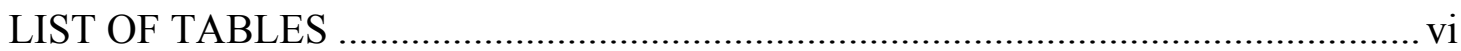

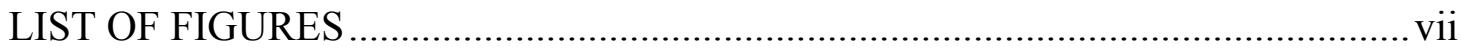

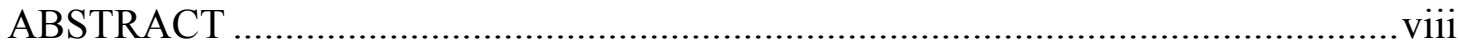

Chapter

1 INTRODUCTION

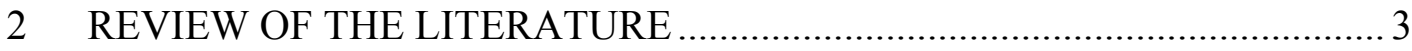

2.1 Types of Congenital Heart Disease ……………......................................... 3

2.1.1 Cyanotic Defects ................................................................... 4

2.1.1.1 Tricuspid Atresia and Pulmonary Atresia ........................ 5

2.1.1.2 Transposition of the Great Arteries ................................ 5

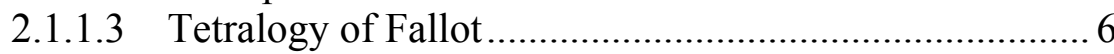

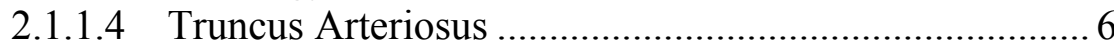

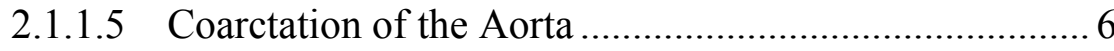

2.1.1.6 Aortic Stenosis........................................................... 7

2.1.1.7 Hypoplastic Left Heart Syndrome................................... 7

2.1.2 Acyanotic Defects ................................................................. 7

2.1.2.1 Patent Ductus Arteriosus ................................................ 8

2.1.2.2 Atrial Septal Defect ....................................................... 8

2.1.2.3 Ventricular Septal Defect ........................................... 8

2.2 Single Versus Biventricular Defects ………………………………..... 9

2.3 Rehospitalization in Infants with CHD ............................................... 9

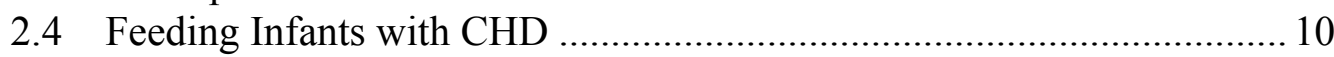

2.5 Breastfeeding Infants with Congenital Heart Disease............................... 11

2.5.1 Barriers to Breastfeeding ………………………....................... 13

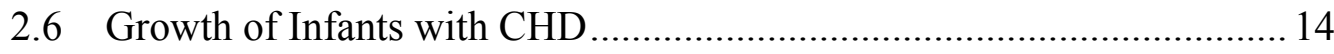

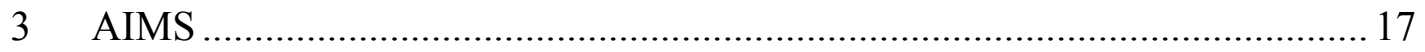




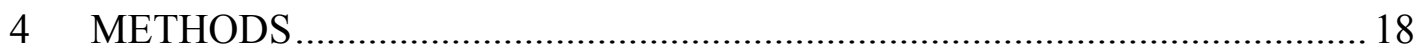

4.1 Subject Recruitment and Informed Consent ........................................ 18

4.2 Study Visit Procedures .......................................................................... 19

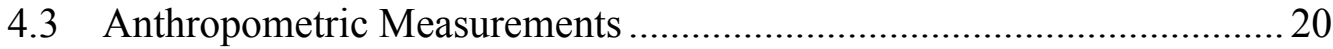

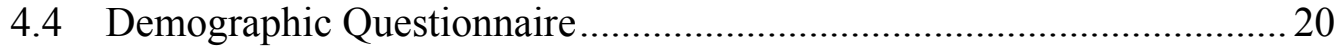

4.5 General Interview Questionnaire....................................................... 21

4.6 Infant Medical History Questionnaire ................................................. 21

4.7 Monthly Infant Feeding Questionnaire ............................................... 21

4.8 Statistical Analysis ................................................................... 22

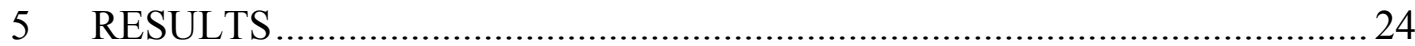

5.1 Demographic Characteristics of Infants and Parents ............................2 24

5.2 Infant CHD Diagnosis ................................................................. 24

5.3 Feeding Type and Feeding Mode in the First Year of Life.................... 24

5.4 Growth in the First Year of Life......................................................2. 25

5.5 Dietary Patterns in the First Year of Life .............................................2 26

5.6 Growth Stratified by Diet Pattern in the First Year of Life.....................26

5.7 Generalized Estimating Equations of Growth by Diet Pattern................ 27

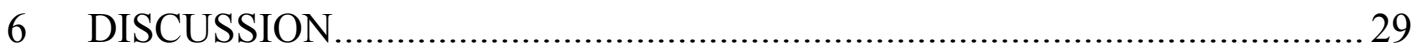

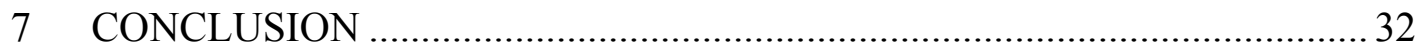

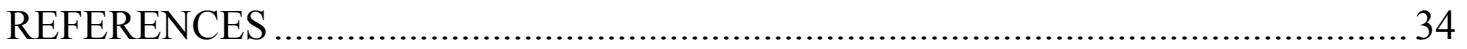

Appendix

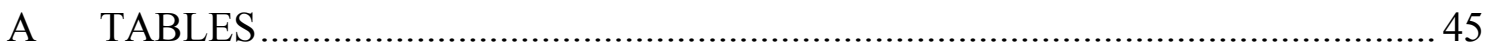

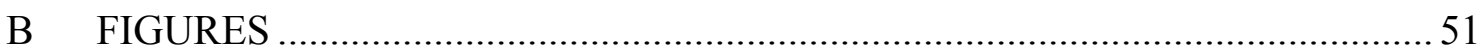

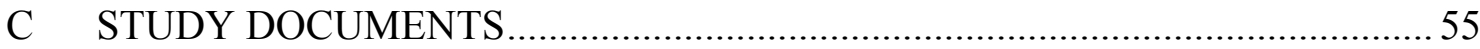




\section{LIST OF TABLES}

Table 1: Demographic Characteristics of Infants and Parents ................................. 45

Table 2: Infant Medical History at Two Weeks of Age .......................................... 46

Table 3: Feeding Type and Mode for 0-4 Months of Age ....................................... 47

Table 4: Feeding Type and Mode for 6-12 Months of Age .................................... 47

Table 5: Anthropometry for 0-4 Months of Age, by Month .................................... 48

Table 6: Anthropometry for 6-12 Months of Age, by Month ................................ 48

Table 7: Cluster Analysis of Diet Patterns in the First Year of Life ..........................48

Table 8: Anthropometry Stratified by Diet Pattern for 0-4 Months of Age ................ 49

Table 9: Anthropometry Stratified by Diet Pattern 6-12 Months of Age....................50 


\section{LIST OF FIGURES}

Figure 1: Weight-for-Length Z-scores by Diet Pattern ..................................... 51

Figure 2: Weight-for-Age Z-scores by Diet Pattern ............................................ 52

Figure 3: Length-for-Age Z-scores by Diet Pattern ............................................ 53

Figure 4: Head Circumference-for-Age Z-scores by Diet Pattern ............................ 54 


\begin{abstract}
Congenital Heart Disease (CHD), the most common form of birth defects in infants, encompasses structural defects of the interior walls, valves, arteries, and/or veins of the heart, which result in abnormal blood flow and impaired cardiac function. For infants with complex CHD, multiple surgical interventions are common within the first year of life. Additionally, these infants often have feeding difficulties and insufficient energy intake, which in turn lead to growth failure. Breastfeeding, the gold standard for infant nutrition, was historically discouraged in this population as it was considered too physiologically laborious. Despite research demonstrating otherwise and the recommendation that infants with CHD be breastfed, misperceptions remain regarding breastfeeding and growth in this population. The purpose of this study was to describe the impact of breastfeeding and other feeding practices on growth outcomes in infants with CHD during the first year of life. Infants with CHD (N=75) who underwent neonatal cardiac surgery within the first two weeks of life were recruited from The Children's Hospital of Philadelphia. Data on infant feeding practices (breast milk, infant formula) and anthropometric measures were collected via nine points of contact spread throughout the first year of life. Cluster analysis of feeding type in the first year of life revealed 3 diet patterns: predominantly breast milk, breast milk transitioning to a mix of breast milk/infant formula, and breast milk
\end{abstract}


transitioning to predominantly infant formula. Generalized estimating equations (GEE) that included diet pattern, time, and their interaction were used to determine if growth trajectories differed by diet pattern. The proportion of infants with CHD in each diet pattern was as follows: $39.5 \%(\mathrm{n}=26)$ were fed 'predominantly breast milk,' $31.8 \%(\mathrm{n}=21)$ were fed 'breast milk and transitioned to a mix of breast milk/infant formula,' and $28.7 \%(\mathrm{n}=19)$ were fed 'breast milk and transitioned to predominantly infant formula.' For growth z-score trajectories in the first year of life, we found no significant group $\mathrm{x}$ time interactions in weight-for-age $(\mathrm{p}=0.072)$, length-for-age $(\mathrm{p}=0.256)$, head circumference-for-age $(\mathrm{p}=0.082)$, and weight-for-length $(\mathrm{p}=0.213)$, indicating infant growth did not differ over time by diet pattern. In conclusion, infants with complex CHD who are predominantly fed breast milk have growth outcomes similar to other diet patterns, and breastfeeding should continue to be encouraged in this population. 


\section{Chapter 1}

\section{INTRODUCTION}

Congenital heart disease (CHD) is the most common form of birth defects in infants, affecting about 40,000 births per year in the United States. ${ }^{1}$ Congenital heart disease encompasses structural defects of the heart that are present upon birth, which result in an abnormal blood flow through the heart and impaired cardiac function. ${ }^{1}$ Many heart defects are not severe, can be treated medically, and resolve as the child grows; however, some are critical and require surgical intervention at birth or soon thereafter. ${ }^{2}$ Infant mortality within the first year of life accounted for $48 \%$ of all mortality caused by CHD from 1999-2006. ${ }^{3}$ This demonstrates the significant impact of some heart defects during the infancy through childhood period.

In addition to the heart defect itself, infants with CHD often present with feeding difficulties such as vomiting ${ }^{4}$, dysphagia ${ }^{5}$, trouble sucking, breathlessness, and impaired absorption. ${ }^{6}$ Such difficulties lead to insufficient energy intake ${ }^{7,8,9}$; therefore, it is common to see growth failure demonstrated by lower than normal weight-for-age, length-for-age, and weight-for-length z-scores in infants with CHD. $8,10,11$

Breast milk is considered the gold standard for infant nutrition, for healthy infants and for those with chronic disease. ${ }^{12}$ However, historically infants with CHD had been encouraged to bottle-feed, as breastfeeding was considered physiologically 
laborious. A study by Marino et al (1995) disproved that theory by demonstrating blood oxygen saturation was higher and less variable (indicating less cardiorespiratory stress) while breastfeeding compared to bottle-feeding infants with CHD. ${ }^{13}$ This research, paired with the known nutritional benefits of breastfeeding, has led to the recommendation that infants with CHD be breastfed. Misperceptions still remain among health professionals regarding breastfeeding and growth in this population, though, as there is little research on the course of breastfeeding (exclusivity and duration) in infants with $\mathrm{CHD}$ and its effect on growth. The goal of this study is to describe breastfeeding and other feeding practices in the first year of life in infants with CHD and to examine their relationship to growth outcomes. 


\section{Chapter 2}

\section{REVIEW OF THE LITERATURE}

\subsection{Types of Congenital Heart Disease}

Congenital heart defects are structural defects of the heart that are present upon birth. The defects can involve the interior walls of the heart, the valves within the heart, or the arteries and veins that carry blood into and out of the heart. These defects result in an abnormal blood flow through the heart and impaired cardiac function. A healthy heart has four working chambers (two atria and two ventricles), and blood is pumped through these chambers by four working heart valves. Blood flow in a healthy heart occurs as follows: deoxygenated blood from the body enters the heart via the right atrium, where it passes through the tricuspid valve into the right ventricle. From the right ventricle, blood is pumped through the pulmonary valve into the pulmonary artery, where it eventually enters the lungs to be oxygenated. From the lungs, oxygenated blood is pumped through the pulmonary veins into the left atrium. From the left atrium, blood is pumped through the mitral valve into the left ventricle, through the aortic valve, and into the aorta. The aorta, then, pumps oxygen-rich blood into the body's circulation. ${ }^{14}$

There are many different types of congenital heart defects. One means of classifying such defects is to whether they are cyanotic or acyanotic. An overarching 
aspect of cyanotic defects is that deoxygenated blood from the right side of the heart is shunted to the left side of the heart without being oxygenated, which results in unoxygenated blood being delivered to the body. A common aspect of acyanotic defects is that some oxygenated blood from the left side of the heart is shunted to the right side of the heart, which increases pulmonary blood flow and pressure. ${ }^{15}$ CHD may be detected in utero with a fetal echocardiogram (ECC) or soon after birth with an electrocardiogram (EKG). In children with a simple defect, such as patent ductus arteriosus or atrial septal defect, surgical intervention may not be required as the condition can often be medically managed. Some of the more severe defects, however, may require immediate surgical intervention upon birth or soon thereafter and followed by additional surgeries at subsequent years in life. ${ }^{2}$

\subsubsection{Cyanotic Defects}

Unoxygenated blood being delivered to the body is a hallmark symptom in infants with cyanotic heart defects. In some defects, the volume of blood being delivered to the body and its tissues is abnormally low due to underdeveloped chambers or blockages in blood vessels. Occasionally, infants with cyanotic defects will appear blue due to a lack of oxygen. ${ }^{2}$ Some of the more common cyanotic heart defects include tricuspid \& pulmonary atresia, transposition of the great arteries, tetralogy of Fallot, truncus arteriosus, coarctation of the aorta, aortic stenosis, and hypoplastic left heart syndrome. 


\subsubsection{Tricuspid Atresia and Pulmonary Atresia}

Tricuspid atresia occurs when the tricuspid valve in the heart is narrow or missing, thus preventing blood flow from the right atrium to right ventricle and subsequently poor oxygenation. Pulmonary atresia is the abnormal development of the pulmonary valve, which controls blood flow from the right ventricle to the main pulmonary artery. This results in blood not being able to flow from the right ventricle of the heart out to the lungs to be oxygenated. ${ }^{2,16}$

\subsubsection{Transposition of the Great Arteries}

Transposition of the great arteries (TGA), the most common of which is dextro-transposition of the great arteries (d-TGA), results in the pulmonary artery and aorta being reversed or transposed. ${ }^{2}$ In a healthy heart, the pulmonary artery carries deoxygenated blood to the lungs for oxygenation and the aorta carries the oxygenated blood from the lungs to the rest of the body. The transposition of these arteries results in deoxygenated blood being pumped out to the body instead of the lungs for oxygenation, and oxygenated blood being pumped from the lungs, into the heart and back to the lungs. ${ }^{17}$ Levo-transposition of the great arteries (1-TGA) involves a "double reversal" of the heart where both the right and left lower chambers and great arteries are reversed, and tends to be a little less severe compared to d-TGA. ${ }^{18}$ 


\subsubsection{Tetralogy of Fallot}

Tetralogy of Fallot involves a combination of four defects: there is a hole between the ventricles (lower chambers of the heart), a partial obstruction from the right side of the heart (the right ventricle and pulmonary valve) impairing blood flow to the lungs, the aorta is in an abnormal position lying over the ventricular septal defect, and an overly thickened (hypertrophied) right ventricle. ${ }^{1,18}$

\subsubsection{Truncus Arteriosus}

In infants with truncus arteriosus, the aorta and pulmonary artery fail to divide and separate completely. Consequently, there is one large artery instead of two separate arteries to carry blood to the lungs and the rest of the body. As a result, unoxygenated blood mixes with oxygenated blood resulting in under-oxygenated blood being delivered to the body. ${ }^{2,18}$

\subsubsection{Coarctation of the Aorta}

Coarctation of the aorta $(\mathrm{CoA})$ involves the narrowing and constricting of the aorta, which affects blood flow by causing the arteries to branch out to carry blood along other vessels to the body. ${ }^{18}$ The narrowing of the aorta leads to high blood pressure and pulsing of blood in the upper body and low blood pressure and weak pulsing in the lower body. ${ }^{16}$ 


\subsubsection{Aortic Stenosis}

Aortic stenosis (AS) occurs when the aortic valve is narrowed and abnormally formed between the left ventricle and aorta, which prevents the valve from opening fully. This reduces or even blocks blood flow into the aorta, making it harder to pump blood out to the rest of the body. ${ }^{2,19}$

\subsubsection{Hypoplastic Left Heart Syndrome}

Hypoplastic left heart syndrome (HLHS) occurs when the left ventricle, mitral valves, aortic valve, and ascending portion of the aorta are underdeveloped, not formed at all, or too small in size. Infants with HLHS often have an atrial septal defect as well, which is a hole between the atria of the heart. ${ }^{16}$

\subsubsection{Acyanotic Defects}

Infants with acyanotic heart defects often have oxygen-rich blood being shunted from the left side of the heart to the right side through an opening or small hole. This results in increased pulmonary blood flow, pulmonary artery pressure, and stress in the lungs. ${ }^{15}$ Examples of acyanotic heart defects include patent ductus arteriosus, atrial septal defect, and ventricular septal defect. 


\subsubsection{Patent Ductus Arteriosus}

Patent ductus arteriosus (PDA) results in the mixing of blood between the pulmonary artery and aorta, due to a hole in the aorta. ${ }^{2,18}$ The hole allows oxygenated blood from the aorta to mix with deoxygenated blood from the pulmonary artery, which stresses the heart and increases blood pressure. ${ }^{1}$

\subsubsection{Atrial Septal Defect}

An atrial septal defect (ASD) is a hole between the atria of the heart, allowing oxygenated blood to flow from the left atrium back into the right atrium instead of to the left ventricle. ${ }^{1}$ This leads to oxygenated blood mixing with deoxygenated blood, and less oxygenated blood being delivered to the body. ${ }^{18}$

\subsubsection{Ventricular Septal Defect}

A ventricular septal defect (VSD) is a hole in part of the ventricles of the heart, which allows oxygenated blood to flow from the left ventricle back into the right ventricle, instead of to the aorta to be pumped out to the body. Smaller VSDs are likely to close on their own, while medium to large VSDs likely require medical or surgical treatment due to the large amount of blood flowing into the right ventricle. This defect leads to increased work for the left side of the heart and blood pressure may become increased in the right side of the heart and lungs. ${ }^{1}$ 


\subsection{Single Versus Biventricular Defects}

While it is common for older studies to classify CHD as either cyanotic or acyanotic, another common way of classifying CHD is either single ventricular physiology or biventricular physiology. A single ventricle (SV) defect occurs when one of the two lower chambers of the heart isn't strong enough to function properly, underdeveloped, or missing a valve. This condition results in the heart only having one pumping chamber instead of two, and can sometimes cause infants to become cyanotic. Some examples of SV defects are HLHS, pulmonary atresia, and tricuspid atresia. $^{20,21}$ Biventricular (BV) defects occur when both of the lower chambers of the heart are of normal physiology. ${ }^{22}$ Some common examples of BV defects include transposition of the great arteries and Tetralogy of Fallot. ${ }^{7,23}$

\subsection{Rehospitalization in Infants with CHD}

Hospital readmissions are common among infants with CHD. A study of 117 children with HLHS and TGA found that $39.3 \%$ of infants with CHD had an unplanned readmission within 4.7 years. ${ }^{24}$ For 36 of these patients, $59 \%$ of these rehospitalizations occurred during the first year of life. ${ }^{24}$ Additionally, a populationbased study of 3,675 hospitalizations among children with CHD found 518 (15\%) readmissions within 31 days of discharge. ${ }^{25}$ Readmission was also more common in those who were classified as having severe congenital heart diagnoses, such as TGA, TOF, and HLHS, compared to those with VSD, ASD, and other acyanotic anomalies. $^{25}$ 
A wide range of factors have been found to influence the frequency of rehospitalization, including being of non-Caucasian ethnicity, lower socioeconomic status, and having co-morbid conditions. ${ }^{26}$ In relation to cardiac surgery, some risk factors for rehospitalization include age at surgery, complexity of diagnosis and surgical intervention, and post-operative feeding difficulties. ${ }^{26}$ Some other significant risk factors found for readmission include respiratory and gastrointestinal complications ${ }^{24}$, single ventricle physiology of the heart, preoperative arrhythmia, longer postoperative length of stay, and nasogastric tube feeding upon discharge. ${ }^{27}$

\subsection{Feeding Infants with CHD}

Adequate nutrition is critical for infants with CHD to support not only age appropriate growth, but also immunity and healing from surgery. ${ }^{28}$ However, infants with CHD typically have trouble achieving adequate nutrient intake due to feeding difficulties. ${ }^{7,829}$ Many infants experience insufficient energy intake due to issues with swallowing, such as uncoordinated sucking and swallowing ${ }^{23}$, dysphagia ${ }^{5}$, poor appetite, vomiting, rapid heartbeat ${ }^{30}$, delayed feeding cues, and for some increased metabolic demand prior to heart surgery. ${ }^{9}$ Additionally, gastrointestinal issues further complicate feeding practices in infants with CHD. Underdevelopment and edema of the GI system impairs digestion and absorption of essential nutrients ${ }^{23}$, in addition to complications such as necrotizing enterocolitis and increased hospital stays. ${ }^{9}$ 
Feeding practices, more specifically the use of infant formula versus breast milk, varies among infants with CHD. A 2009 retrospective case series of 100 infants who underwent the bidirectional Glenn procedure for HLHS found that majority of patients, at a mean age 5.1 months, were formula fed, with only $9 \%$ receiving breast milk at the time of surgery and $24 \%$ receiving breast milk at hospital discharge. ${ }^{31}$ Similarly, a study based on a subsample of the Norwegian Mother and Child Cohort Study found that infants with CHD were fed breast milk less frequently compared to healthy infants during the first six months of life. At 6 months of age, $9.9 \%$ of the infants with CHD were mainly given breast milk compared to $14.7 \%$ in the control group. ${ }^{32}$ However, these studies were published in 2009, and a 2015 study describing breastfeeding rates among 62 mothers that gave birth to infants at CHOP Special Delivery Unit found that $89 \%$ planned to pump or breastfeed and $96 \%$ initiated lactation via pumping after giving birth. Additionally, over $70 \%$ of the feeding was from breast milk. ${ }^{33}$

\subsection{Breastfeeding Infants with Congenital Heart Disease}

Breastfeeding was historically believed to be too physiologically laborious for the infant with CHD, thereby putting more respiratory stress on the child, compared to bottle-feeding. However, a study from Marino et al (1995) demonstrated that blood oxygen saturation was actually higher and less variable while breastfeeding compared

to bottle-feeding infants with CHD, which indicates less cardiorespiratory stress. ${ }^{13}$ For 
all infants (healthy or with non-contraindicated chronic disease), the American Academy of Pediatrics ${ }^{34}$, World Health Organization ${ }^{35}$, the American Dietetic Association ${ }^{36}$, and the American College of Obstetricians and Gynecologists ${ }^{37}$ recommend exclusive breastfeeding for the first 6 months of life, followed by continued breastfeeding in addition to complementary foods until at least 12 months of age. Breast milk is considered the gold standard for infant nutrition providing nutrients and other components that confer physiologic benefit to the infant. ${ }^{12}$ If feeding directly from the breast (breastfeeding) is not an option or is not possible, the infant can receive expressed breast milk via tube or bottle. ${ }^{38}$

The World Health Organization has established criteria for classifying the different breastfeeding practices. ${ }^{39}$ The term 'exclusive breastfeeding' requires that the infant only receive breastmilk (including donor breast milk) without any additional food or drink, not even water; oral rehydration solution, drops, syrups, vitamins, minerals, and medicines are allowed, however. The term 'predominant breastfeeding' requires that the infant receive breast milk as the predominant source of nourishment, with certain liquids, ritual fluids, and oral rehydration solutions allowed when needed. 'Complementary feeding' requires that the infant receive breast milk in addition to any other food or liquid, including non-human milk, formula, and solid or semi-solid foods. 'Bottle-feeding' is defined as the infant receiving any liquid, including breastmilk, from a bottle with a nipple, and may include any additional food or liquid. 39. The Interagency group for action on breastfeeding focuses definitions on the source of nutrients, not the feeding mode. In this case, 'full breastfeeding' can be 'exclusive' 
meaning breast milk with no other liquids or solids are given to the infant; or 'almost exclusive' with breast milk, vitamins, minerals, water, juice, ritualistic feeds given to the infant. The term 'partial breastfeeding, high' is used when more than $80 \%$ of feedings are breastmilk feedings; 'partial breastfeeding, medium' is used when between 20 to $80 \%$ of feedings are breastmilk, and 'partial breastfeeding, low' is used when less than $20 \%$ of feedings are breast milk. Lastly the term 'token breastfeeding' is when there are minimal, occasional, or irregular breastfeeds. ${ }^{40}$

\subsubsection{Barriers to Breastfeeding}

Despite the various benefits of breastfeeding, many mothers experience difficulties and barriers to breastfeeding their infant with CHD. Among those barriers, one that stands out among the literature, albeit older literature, includes receiving little to no encouragement from hospital staff in breastfeeding. ${ }^{41,42}$ Other barriers reported in literature (1998) include maternal fatigue, anxiety, separation from infant, and institutional policy barriers such as lack of privacy, inconsistent recommendations and lack of breastfeeding support from health care providers. ${ }^{41}$ A study of 62 mothers of post-operative infants with CHD reported mothers initially feeling as though hospital staff encouraged them to use formula rather than breastfeeding. ${ }^{41}$ Mothers stated that babies were often given bottle feeds before breastfeeding attempts and initiation of breastfeeding was often delayed. ${ }^{42}$ Mothers reported stress over infant feeding and anxiety related to infant growth, demonstrating a need for parenteral support related to feeding upon hospitalization and discharge. ${ }^{4}$ 


\subsection{Growth of Infants with CHD}

Growth failure is common among infants with CHD. ${ }^{8,10,11,29,43-52}$ Of the 14 studies identified that measured growth in infants with CHD, poor growth was reported in all of them. A study of 1-45 month old infants with cyanotic and acyanotic CHD found that $56 \%$ of infants were below the $5^{\text {th }}$ percentile for weight and $41 \%$ were below the $5^{\text {th }}$ percentile for both weight and height. ${ }^{43}$ Similarly, a study of 48 children with CHD, some of which include ASD, VSD, TOF, and TGA, ranging in age from 2 days to 4.77 years old reported that $52 \%$ had a weight below the $3^{\text {rd }}$ percentile and $37 \%$ had a height and length below the $3^{\text {rd }}$ percentile. ${ }^{44}$ It appears that early cardiac surgery may improve growth outcomes. A study of 38 children ranging in age from 0 to 352 days with CHD reported weight-for-age (WAZ) and length-for-age (LAZ) Zscores of those who underwent surgery within the first 10 days of life to be $0.40 \pm 1.36$ and $-0.65 \pm 1.46$ respectively, compared to those who underwent surgery after 10 days of age to be $-1.13 \pm 0.94$ and $-1.39 \pm 1.09 .{ }^{45}$ Additionally, it appears that some growth failure may occur during treatment. A study of 61 infants with CHD (56\% with HLHS) reported a mean decrease in WAZ of $-1.5 \pm 0.8$ between surgery at a median age of 4 days and hospital discharge at a median age of 22 days. Upon surgery, $5 \%$ of the study sample was below a Z-score of -2.0 but upon discharge $41 \%$ were below $-2.0 .{ }^{11}$ While these studies certainly demonstrate poor growth in infants with CHD, they fail to mention specifics on feeding practices (e.g. breast milk or formula.) 
We identified 7 studies that described both the type of feeding and growth of infants with CHD. ${ }^{8,10,31,46-49}$ One study of infants 95.5 days old, who were fed breast milk or formula, found that the mean WAZ and LAZ scores of 44 infants with CHD was -1.1 and -0.7 , respectively, compared to the mean WAZ and LAZ scores of 49 healthy control infants at -0.3 and 0.0 , respectively. ${ }^{10}$ Another study of 18 infants, 3-5 month of age, with 8 infants having moderate to large VSDs and 10 healthy agematched control infants, found that those with VSD had significantly lower weight $(\mathrm{p} \leq 0.05)$ and length $(\mathrm{p} \leq 0.005)$ and weighed significantly less since birth ( $p \leq 0.005)$, compared to the control infants. Three out of the eight infants with CHD in this study were formula fed, while the control infants were given formula or breast milk. ${ }^{46}$ It was found that at a mean age of 4.15 months, weight and length of infants with VSD/no CHF and VSD/with CHF were significantly lower than healthy age-matched control infants (control: $7.1 \mathrm{~kg} / 64.3 \mathrm{~cm}$, VSD/no CHF: $5.6 \mathrm{~kg} / 60.4 \mathrm{~cm}$, VSD/CHF: $4.9 \mathrm{~kg} / 59.9 \mathrm{~cm}) .{ }^{47}$ The VSD/no CHF group received formula, and five out of the seventeen VSD/CHF group received formula or fortified breast milk. ${ }^{47}$ Lastly, another study found that the weight of 10 infants with cyanotic CHD who weighed $3.25 \mathrm{~kg}$ and $5.28 \mathrm{~kg}$ at 2 weeks and 3 months of age, respectively, was significantly less than the 12 control infants who weighed $3.86 \mathrm{~kg}$ and $6.21 \mathrm{~kg}$, at the same age. All infants were either fed breast milk or formula. ${ }^{48}$

Unfortunately, adequate weight gain and growth is an issue even while in the hospital. A study of 65 infants with CHD reported a median WAZ score of -0.7 at the time of systemic-to-pulmonary artery shunt palliation, which decreased to -1.6 at the 
time of transfer to cardiac step-down unit, and -2.0 at time of discharge. This represents an overall median WAZ decrease of 1.3 standard deviations from time of cardiac surgery to hospital discharge ${ }^{8}$ A similar study of 100 children with CHD reported a median WAZ of -0.3 upon hospital admission and a median WAZ of -1.3 upon bidirectional Glenn procedure at the median age of 5.1 months old. ${ }^{31}$ All infants in the preceding 2 articles were fed a mix of breast milk and formula.

Growth failure tends to be related to the severity of CHD and the type of surgical intervention. Infants undergoing Norwood palliation (typically for infants with HLHS) had a significantly greater decrease in WAZ score compared to those undergoing non-Norwood palliation. ${ }^{8}$ Another study reported that infants with HLHS weighed significantly less than those with d-TGA at 1 month $(3.29 \pm 0.58$ vs $3.70 \pm$ $0.60 \mathrm{~kg} ; \mathrm{p}=0.021), 6$ months $(6.27 \pm 1.06$ vs $7.31 \pm 1.02 \mathrm{~kg} ; \mathrm{p}=0.003)$, and 12 months of age $(8.40 \pm 1.11 \mathrm{vs} 9.49 \pm 1.01 \mathrm{~kg} ; \mathrm{p}=0.006) .{ }^{49}$ All infants in the preceding 2 articles were fed a mix of breast milk and formula.

While some studies reporting growth outcomes of infants with CHD have elaborated on infant feeding details ${ }^{50,51}$, only one has compared feeding type to growth outcomes. Combs and Marino (1993) reported that bottle-fed infants with CHD fell significantly farther from their growth curves than the breastfed infants did. ${ }^{52}$ Despite these small findings, there is a need to further evaluate the impact of feeding practices (breast milk versus formula) longitudinally on growth outcomes in this population. 


\title{
Chapter 3
}

\begin{abstract}
AIMS
The overall aims of this study are to describe breastfeeding and other feeding practices in the first year of life in infants with CHD and to examine their relationship to growth outcomes through a longitudinal, observational study.
\end{abstract}

\section{Specific Aim 1: Describe the type of feeding and mode of feeding of infants with} CHD during the first year of life. We hypothesized that the proportion of infants with CHD who were predominantly breastfed or receiving any breastmilk during the first year of life would be comparable to the general population, as it has been shown mothers can successfully breastfeed their infant with CHD with proper support and education. $^{33,42}$

\section{Specific Aim 2: Describe growth outcomes among infants with CHD during the} first year of life, and the relationship between feeding practices and growth. We hypothesized that there would be better growth outcomes (weight-for-age, length-forage, head circumference-for-age, and weight-for-length Z-scores) in the infants that were predominantly breastfed or fed any breast milk compared to those that were predominantly formula fed, as it has been shown before that bottle-fed infants fell further from their growth curves than breastfed infants did. ${ }^{52}$ 


\section{Chapter 4}

\section{METHODS}

\subsection{Subject Recruitment and Informed Consent}

Prior to study initiation, the Institutional Review Board (IRB) at The Children's Hospital of Philadelphia (CHOP) and the IRB at the University of Delaware approved the protocol, procedures, and questionnaires for this study.

The study enrolled 75 mother-infant dyads from the Cardiac Intensive Care Unit (CICU) at The Children's Hospital of Philadelphia. In order to participate in the study, the eligibility criteria required infants must have been born full term ( $\geq 37$ and $\leq 42$ weeks gestation at birth), singleton, appropriate for gestational age, been diagnosed with congenital heart disease (CHD), have undergone or will undergo neonatal corrective or palliative surgery prior to discharge, and between the age of 0 -

21 days old at enrollment. The mother must have been $\geq 18$ years old, English speaking, and planning to breastfeed. Exclusion criteria requires that the infant not have any other known physical, neurological, or physiological anomalies that are known to affect feeding (e.g. cleft palate or inborn errors of metabolism).

The Principal Investigator, the cardiac lactation consultant, at the Children's Hospital of Philadelphia approached the potential subjects/parents from the CICU. The informed consent was reviewed and mothers were given the opportunity to ask 
questions. If the informed consent procedure was signed, the subject was assigned a unique identification number.

\subsection{Study Visit Procedures}

The study consisted of nine contact points throughout the first year of life. The first contact (or visit) occurred during the first two weeks of life while the infant was still hospitalized, and the remainder of the study contacts occurred at 1, 2, 3, 4, 6, 8, 10, and 12 months of age. Each contact occurred as either an inpatient visit or telephone call if the subject had been discharged to home.

The first visit occurred in the CICU, when the infant was approximately two weeks of age. This initial visit consisted of the following questionnaires: demographic questionnaire, general interview questionnaire, infant feeding questionnaire, and infant medical history questionnaire. The second visit occurred either in the hospital or at home depending on the subject, and consisted of an infant feeding questionnaire. The rest of the visits (visits three through nine) consisted of an infant feeding questionnaire. The questionnaires used in this study were adapted for our specific population from the Feeding Infants and Toddlers Study (FITS), which is a crosssectional survey of nutrient intake and breastfeeding practices among infants, toddlers, and preschoolers in the United States started in $2002 .{ }^{53}$ See the Appendix C for all study questionnaires. 


\subsection{Anthropometric Measurements}

The anthropometrics measurements taken for this study included infant weight, length, and head circumference. These measures were collected for every subject contact by standard procedure. Weight was measured using a digital scale accurate to 0.001 kilograms, length was measured using an infantometer accurate to $0.1 \mathrm{~cm}$, and head circumference was measured using a non-elastic tape measure accurate to 0.1 $\mathrm{cm}$. These data were then entered into the electronic health record and downloaded into the database. Anthropometric measurements were recorded from electronic health records if the infant received care, either inpatient or outpatient, within the CHOP network. If the infant received care out of the CHOP care network, the infant's primary care provider was contacted by the Principal Investigator to obtain the infant's weight, length, and head circumference.

\subsection{Demographic Questionnaire}

At the first study visit, the demographic questionnaire was completed. This questionnaire obtained information regarding maternal and paternal age, race, education, ethnicity, occupation, and participation in government programs [e.g. Special Supplemental Nutrition Program for Women, Infants, and Children (WIC)]. 


\subsection{General Interview Questionnaire}

At the first study visit, the general interview questionnaire was completed. This questionnaire collected information about maternal and paternal age, height, weight, and marital status. This questionnaire also obtained the age and gender of the infant, as well as the age and gender of the infant's siblings. Additional data on those living in the household with the infant was collected in this questionnaire.

\subsection{Infant Medical History Questionnaire}

At the first study visit, the infant medical history questionnaire was completed. This questionnaire obtained information regarding the infant's CHD diagnosis, gestational age, birth weight, birth length, other additional diagnoses besides CHD, and surgical history of the infant.

\subsection{Monthly Infant Feeding Questionnaire}

A Monthly Infant Feeding Questionnaire was completed at each study visit. This questionnaire collected information related to feeding practices such as breastfeeding and bottle-feeding practices, formula feeding practices, tube feeding practices, pumping breast milk, frequency and duration of feedings, and donor milk usage. 


\subsection{Statistical Analysis}

Data from the study was entered into REDCap, a secure web-based electronic data capture and management system. Descriptive statistics were used to describe feeding practices and growth in infants with CHD within the first year of life. Continuous variables were summarized using number of observations, mean, median, standard deviation, and standard error. Categorical variables were summarized using frequency and percentages of subjects.

\section{Specific Aim 1: Describe type of feeding and mode of feeding of infants with CHD}

during the first year of life. With respect to type of feeding, the number and percentage of infants receiving breast milk (BM) only [predominantly], breast milk fortified with powder formula, breast milk mixed with formula, formula only [predominantly], a combination of formula and non-infant formula milk, and noninfant formula milk only were summarized for each contact. With respect to mode of feeding, the number and percentage of infants being: exclusively fed at the breast, a mix of breastfeeding and bottle-feeding, mix of breastfeeding and tube feeding, exclusively fed via bottle, a mix of bottle-feeding and tube feeding, a mix of breastfeeding, bottle-feeding and tube feeding, or exclusive tube feeding were summarized for each contact. Cluster analysis of diet type (breast milk, infant formula) at each contact point was used to determine overall diet pattern. 


\section{Specific Aim 2: Describe growth outcomes among infants with CHD during the}

first year of life, and the relationship between feeding practices and growth.

Growth measures (weight, length, head circumference) were converted to weight-forage (WAZ), length-for-age (LAZ), head circumference-for-age (HCZ), and weightfor-length (WLZ) Z-scores based on the World Health Organization growth standards. Growth Z-scores were summarized (mean \pm standard deviation) for each study visit. Generalized estimating equations (GEE) that included diet pattern, time, and their interaction were used to determine if growth Z-score trajectories differed based on diet patterns that the infants received throughout the first year of life (breast milk transitioning to predominantly breast milk, breast milk transitioning to a mix of breast milk and infant formula, and breast milk transitioning to predominantly infant formula). 


\section{Chapter 5}

\section{RESULTS}

\subsection{Demographic Characteristics of Infants and Parents}

Parent and infant demographic characteristics for the 75 mother-infant dyads are reported in Table 1. Fifty-five (73\%) of the infants were male, the majority (95\%) were Non-Hispanic or Latino, and $81 \%(n=60)$ were white or Caucasian. The majority of mothers $(61 \%, n=45)$ and fathers $(57 \%, n=41)$ reported completing one to four years of college education. Additionally, $31 \%(n=23)$ of mothers and $22 \%(n=16)$ of fathers reported completing more than four years of college education in graduate school. The mean maternal and paternal age was $30.7 \pm 4.6$ years and $32.3 \pm 5.4$ years, respectively.

\subsection{Infant CHD Diagnosis}

Infant medical history and primary diagnoses at two weeks of age are reported in Table 2. The most common primary congenital heart disease diagnosis was hypoplastic left heart syndrome (HLHS, 45\%, n=34), with the next most common being dextro-Transposition of the great arteries (TGA-D, 15\%, n=11) and truncus arteriosus (TA, 11\%, $\mathrm{n}=8$ ).

\subsection{Feeding Type and Feeding Mode in the First Year of Life}

Feeding type and feeding mode throughout the first year of life are reported in Table 3 (0-4 months) and Table 4 (6-12 months). At 2 weeks of age, majority of 
infants $(96 \%)$ were fed breast milk alone or in conjunction with infant formula. More specifically, $82 \%(n=61)$ of the infants were receiving predominantly breast milk and $14 \%(n=10)$ were receiving a mix of breast milk and formula. The mode of feeding at 2 weeks of age varied with $64 \%$ of infants $(n=47)$ fed through a combination of breastfeeding, bottle-feeding, and tube feeding.

By 6 months of age, infant formula became more prevalent with $44 \%(n=31)$ of infants being predominantly formula fed. Breast milk was still utilized, though, as $29 \%(n=20)$ of infants were being fed a mix of breast milk and formula and $27 \%$ $(n=19)$ infants were predominantly fed breast milk. With respect to feeding mode, just over half of infants $(51 \% ; n=36)$ were fed exclusively via a bottle at 6 months of age. Others were fed via a mix of tube feeding and bottle-feeding $(14 \% ; n=10)$ or a mix of breastfeeding and bottle-feeding $(11 \% ; n=8)$.

By 1 year of age, just over one-half $(54 \%$; $n=35)$ of infants were predominantly fed infant formula. Yet, $23 \%(n=15)$ of the infants were fed predominantly breast milk and a mix of breast milk and formula was given to $9 \%$ $(n=6)$ of infants. With respect to mode of feeding, the majority $(72 \% ; n=47)$ of infants were fed exclusively via bottle, followed by $9 \%(n=6)$ infants fed exclusively at the breast.

\subsection{Growth in the First Year of Life}

Growth outcomes in the first twelve months of life are described by weightfor-age (WAZ), length-for-age (LAZ), head circumference-for-age (HCZ), and weight-for-length (WLZ) Z-scores (Table 5, 0-4 months; Table 6, 6-12 months). At 2 weeks of life (study enrollment), the mean WAZ, LAZ, HCZ, and WLZ for all infants in the study were $-0.6 \pm 1.0,-0.8 \pm 1.1,-1.0 \pm 1.1$, and $-0.3 \pm 1.0$, respectively. At 6 
months of age, the mean WAZ, LAZ, HCZ, and WLZ for all infants were $-0.9 \pm 1.0$, $0.8 \pm 1.1,-0.3 \pm 0.9$, and $-0.5 \pm 1.1$, respectively. By 12 months of age, the mean WAZ, LAZ, HCZ, and WLZ Z-scores for all infants in the study were $-0.3 \pm 1.0,-0.5$ $\pm 1.2,0.1 \pm 0.9$, and $0.0 \pm 1.0$, respectively.

\subsection{Dietary Patterns in the First Year of Life}

Cluster analysis revealed three different diet patterns (Table 7). The first dietary pattern observed, "BM to Predominantly BM," was assigned to infants who received breast milk as their predominant source of nutrition throughout the first year of life. The second pattern, "BM to Mix of BM/Formula," was assigned to those who received breast milk from two weeks of age up to the first month of age, and then transitioned to a mix of breast milk and infant formula for the remaining months in the first year of their life. The last pattern, "BM to Predominantly Formula," was assigned to those who received breast milk from two weeks of age up to the first month of age, and then transitioned to predominantly infant formula for the remaining months of the first year of life. Just over one-third $(39.5 \%$; $n=26)$ of infants were fed predominantly breast milk throughout the first year of their life. Twenty-one infants (31.8\%) received breast milk during the first month of their life, and then received a mix of breast milk and formula for the remaining 11 months of their first year of life. Nineteen infants (28.7\%) received breast milk during the first month of their life, and then transitioned to predominantly infant formula for the remaining 11 months of their first year of life.

\subsection{Growth Stratified by Diet Pattern in the First Year of Life}

Growth over the first year of life was stratified by the three dietary patterns (BM to Predominantly BM, BM to Mix BM/Formula, and BM to Predominantly 
Formula (Table 8, 0-4 months; Table 9, 6-12 months). At two weeks of age, infants classified as "BM to Predominantly BM," had a mean WAZ, LAZ, HCZ, and WLZ of $-0.3 \pm 0.1,-0.7 \pm 0.2,-1.0 \pm 0.2$, and $0.0 \pm 0.2$, respectively. By six months of age, the mean WAZ, LAZ, HCZ, and WLZ was $-0.6 \pm 0.1,-0.6 \pm 0.2,-0.4 \pm 0.2$, and $-0.2 \pm$ 0.2 , respectively. At twelve months of age, the mean WAZ, LAZ, HCZ, and WLZ was $-0.1 \pm 0.1,-0.5 \pm 0.2,0.1 \pm 0.2$, and $0.1 \pm 0.2$, respectively

At two weeks of life for infants classified as "BM to Mix BM/ Formula," had a mean WAZ, LAZ, HCZ, and WLZ of $-0.6 \pm 0.2,-0.6 \pm 0.2,-0.9 \pm 0.2$, and $-0.4 \pm 0.2$, respectively. By six months of age, the mean WAZ, LAZ, HCZ, and WLZ was $-1.2 \pm$ $0.2,-0.7 \pm 0.2,-0.2 \pm 0.2$, and $-1.0 \pm 0.2$, respectively. At twelve months of age, the mean WAZ, LAZ, HCZ, and WLZ was $-0.3 \pm 0.2,-0.5 \pm 0.2,0.2 \pm 0.2$, and $-0.1 \pm 0.2$, respectively.

At two weeks of life for infants classified as "BM to Predominantly Formula," had a mean WAZ, LAZ, HCZ, and WLZ of $-0.8 \pm 0.2,-1.0 \pm 0.2,-0.9 \pm 0.2,-0.4 \pm$ 0.2 . By six months of age, the mean WAZ, LAZ, HCZ, and WLZ was $-0.9 \pm 0.2,-1.1$ $\pm 0.2,-0.4 \pm 0.2$, and $-0.2 \pm 0.2$, respectively. At twelve months of age, the mean WAZ, LAZ, HCZ, and WLZ was $-0.2 \pm 0.2,-0.3 \pm 0.2,0.1 \pm 0.2$, and $0.0 \pm 0.2$, respectively.

\subsection{Generalized Estimating Equations of Growth by Diet Pattern}

Generalized estimating equations that included diet pattern group (BM to Predominantly BM, BM to Mix BM/Formula, and BM to Predominantly Formula) time, and their interaction (group $\mathrm{x}$ time) on anthropometric outcomes were assessed (Figures 1 - 4). The GEE approach accounts for the repeated measurements 
of outcomes over time for each infant and examines whether the slopes of the line created differs between treatment groups. All generalized estimating equations revealed no significant group $x$ time interactions in WLZ $(p=0.213)$, WAZ $(p=0.072)$, LAZ (0.256), and HCZ ( $\mathrm{p}=0.082)$, indicating that infant growth trajectory did not differ by diet pattern over time. 


\section{Chapter 6}

\section{DISCUSSION}

The overall aim of this study was two-fold. First we sought to describe breastfeeding and other feeding practices throughout the first year of life in infants with CHD. Second, we wanted to examine the relationship between infant diet patterns and growth outcomes. Interestingly, we found that proportion of infants with CHD who are predominantly breastfed or receive any breastmilk during the first year of life was comparable to that of the general population. According to the CDC 2018 Breastfeeding Report Card reporting data through 2015, the percentage of infants in the United States that are breastfed at 6 and 12 months of age was $57.6 \%$ and $35.9 \%$,

respectively. ${ }^{54}$ These rates are comparable to the percentage of infants breasted in our study, with $56 \%$ and $32 \%$ of the infants breastfed at 6 and 12 months of age, respectively. These results demonstrate that it is possible for infants with CHD to breastfeed and/or receive breast milk during the first year of life and that the proportion of those with CHD that are breastfed or receiving breastmilk is comparable to the general population.

The second aim of this study was to describe growth in infants with CHD over the first year of life and to determine if there were differences in growth outcomes based on the infants' diet pattern. The average WAZ, LAZ, HCZ, and WLZ Z-scores 
for all infants in our study were below zero, which indicated their growth parameters were in the lower $50^{\text {th }}$ percentile. These Z-score measures decreased over time, especially during the first few months of life, which indicated that the growth of CHD infants was lower than that of the general population. By 12 months of age, however, average Z-scores for the infants were closer to zero, which may indicate that growth among infants with CHD has the potential to normalize with increasing age. This is consistent with what is seen in the literature where infants with CHD demonstrate growth failure as evidenced by lower than normal Z-scores ${ }^{8,10,11,29,43-52}$; however, some of these studies are cross-sectional and do not continue to follow the infants to 12 months of age. The declining Z-scores seen in the first few months of life could be a result of negative energy balance during hospitalization. Insufficient energy intake has been reported in infants with CHD during the perioperative period. ${ }^{23,56}$ This is consistent with research that found an overall median WAZ decrease of 1.3 standard deviations from time of cardiac surgery to hospital discharge in infants with CHD. ${ }^{8}$

To our knowledge, this is the first study to longitudinally evaluate growth in infants with CHD based on feeding type. Ultimately, there were no significant differences in growth based on whether the infant was fed predominantly breast milk, fed breast milk transitioning a mix of breast milk and infant formula, or fed breast milk transitioning to predominantly infant formula. These results suggest that breast milk supports growth of infants with congenital heart disease as evidenced by growth outcomes that are similar to those transitioning to a mix of breast milk of infant 
formula or transitioning to solely breast milk. Breastfeeding should continue to be encouraged in this population by healthcare professionals, and mothers should feel confident that breastfeeding/providing breast milk to their infants with CHD will not have negative impacts on growth outcomes compared to other diet patterns that included infant formula.

The strengths of this study include its prospective and longitudinal nature with repeated measures of diet and growth throughout the first year of life. A limitation of this study is the overall number of participants, which resulted in small groups for analysis when stratified by feeding pattern. Additionally, collecting anthropometric data from infants' primary care physicians after discharge for those outside of the CHOP care network was difficult and often resulted in missing data. Therefore, we used an intention-to-treat (ITT) analysis where at least one Z-score per visit was needed to include the infant in analysis for that contact point. The last limitation that was majority of our population was male. However, gender has not been reported to have an impact on growth in those with CHD to our knowledge. This relationship could be further examined in the future, but could not be found in our study due to small sample size. 


\section{Chapter 7}

\section{CONCLUSION}

It is well established that infants with CHD often experience feeding difficulties that lead to insufficient energy intake, which in turn negatively affects

growth. ${ }^{7-11}$ What is not known, however, is the course of growth longitudinally in infants with CHD with respect to feeding breastmilk and/or infant formula. Two of the key findings from this study were that 1) slightly over $1 / 3$ of infants with CHD were predominantly fed breast milk throughout the first year of life and other $1 / 3$ received breast milk and then transitioned to a mix of breast milk and infant formula; and 2) infant growth trajectories through 12 months of age did not differ based on diet pattern ("BM to Predominantly BM", "BM to Mix of BM/Formula", and "BM to Predominantly Formula.") These findings are of particular interest since the majority of the infants in the study had a severe heart defect, namely hypoplastic left heart syndrome (HLHS, $45 \%, \mathrm{n}=34$ ). HLHS is a single ventricle defect that has been shown to result in poorer growth patterns compared to other defects. ${ }^{49}$

Future analysis of data from this study will explore the impact of CHD severity on diet patterns and growth. It has been shown that infants with single ventricle heart defects are associated with increased hospital length of stay ${ }^{55}$, and poorer growth outcomes ${ }^{10}$, thus CHS severity may impact the relationship between diet patterns and growth. Additionally, an analysis of the relationship between diet patterns, growth, 
and re-hospitalization in the first year of life could be performed in the future. Predictors of re-hospitalization include having postoperative feeding difficulties, comorbid conditions, respiratory and gastrointestinal complications, and longer postoperative stays. ${ }^{24,26,27}$ Therefore, an exploration of this relationship in our sample may reveal if infants who were not re-hospitalized during the first year of life had better growth outcomes compared to those who were re-hospitalized $\geq 1$ time.

There is a lack of research in diet patterns and growth of infants with CHD, thus making our study one of the first to study this relationship longitudinally. The results of this study provide support for medical professionals to continue to encourage breastfeeding/feeding breastmilk in this population and provide evidence to mothers that they can breastfeed/provide breast milk to their infants with CHD. 


\section{REFERENCES}

1. Congenital Heart Defects. National Heart, Lung, and Blood Institute Web site. https://www.nhlbi.nih.gov/health-topics/congenital-heart-defects. Accessed April 16, 2018.

2. Congenital Heart Disease. The Children's Hospital of Philadelphia Web site. http://www.chop.edu/conditions-diseases/congenital-heart-disease. Accessed April 16, 2018.

3. Gilboa SM, Salemi JL, Nembhard WN, Fixler DE, Correa A. Mortality resulting from congenital heart disease among children and adults in the united states, 1999 to 2006. Circulation. 2010;122(22):2254-2263. doi:

10.1161/CIRCULATIONAHA.110.947002.

4. Hartman D, Medoff-Cooper B. Transition to home after neonatal surgery for congenital heart disease. MCN, The American Journal of Maternal/Child Nursing. 2012;37(2):95-100. doi: 10.1097/NMC.0b013e318241dac1. 
5. Kohr LM, Dargan M, Hague A, et al. The incidence of dysphagia in pediatric patients after open heart procedures with transesophageal echocardiography. Ann Thorac Surg. 2003;76(5):1450-1456.

6. Clemente C, Barnes J, Shinebourne E, Stein A. Are infant behavioural feeding difficulties associated with congenital heart disease? Child: Care, Health and Development. 2001;27(1):47-59. doi: 10.1046/j.1365-2214.2001.00199.x.

7. Schwalbe-Terilli CR, Hartman DH, Nagle ML, et al. Enteral feeding and caloric intake in neonates after cardiac surgery. American Journal of Critical Care. 2009;18(1):52-57.

8. Nicholson GT, Clabby ML, Kanter KR, Mahle WT. Caloric intake during the perioperative period and growth failure in infants with congenital heart disease. Pediatr Cardiol. 2013;34(2):316-321. doi: 10.1007/s00246-012-0448-8.

9. Hubschman LE. Malnutrition in congenital heart disease: Management to improve outcomes. ICAN: Infant, Child, \& Adolescent Nutrition. 2013;5(3):170-176. doi: 10.1177/1941406413485906. 
10. Irving SY, Medoff-Cooper B, Stouffer NO, et al. Resting energy expenditure at 3 months of age following neonatal surgery for congenital heart disease. Congenital Heart Disease. 2013;8(4):343-351. doi: 10.1111/chd.12035.

11. Medoff-Cooper B, Irving SY, Marino BS, et al. Weight change in infants with a functionally univentricular heart: From surgical intervention to hospital discharge. Cardiol Young. 2011;21(2):136-144. doi:10.1017/S104795111000154X

12. Walker, A. Breast milk as the gold standard for protective nutrients. Journal of Pediatrics. 2010; 156 (2). doi: //doi.org/10.1016/j.jpeds.2009.11.021

13. Marino BL, O'Brien P, LoRe H. Oxygen saturations during breast and bottle feedings in infants with congenital heart disease. Journal of Pediatric Nursing. 1995;10(6):360-364. doi: 10.1016/S0882-5963(05)80033-8.

14. How the Healthy Heart Works. American Heart Association Web site. http://www.heart.org/HEARTORG/Conditions/CongenitalHeartDefects/AboutCongen italHeartDefects/How-the-Healthy-HeartWorks_UCM_307016_Article.jsp\#.WtZFS9Pwbwd. Updated January 9, 2017. Accessed April 17, 2018. 
15. Baffa JM. Overview of Congenital Cardiovascular Anomalies. Merck Manual Web site. https://www.merckmanuals.com/professional/pediatrics/congenitalcardiovascular-anomalies/overview-of-congenital-cardiovascularanomalies? $\mathrm{qt}=$ congenitlheartdisease $\&$ alt $=$ sh. Updated November 2016. Accessed April 17, 2018.

16. Specific Heart Defects. Center for Disease Control and Prevention Web site. https://www.cdc.gov/ncbddd/heartdefects/specificdefects.html. Updated September 26, 2016. Accessed April 17, 2018.

17. Transposition of the Great Arteries. The Society of Thoracic Surgeons Web site. http://ctsurgerypatients.org/pediatric-and-congenital-heart-disease/transposition-ofthe-great-arteries. Reviewed December 2017. Accessed April 17, 2018.

18. Common Types of Heart Defects. American Heart Association Web site. http://www.heart.org/HEARTORG/Conditions/CongenitalHeartDefects/AboutCongen italHeartDefects/Common-Types-of-HeartDefects_UCM_307017_Article.jsp\#.WtZJQ9Pwbwc. Updated January 9, 2017. Accessed April 17, 2018. 
19. Aortic Valve Stenosis. Mayo Clinic Web site.

https://www.mayoclinic.org/diseases-conditions/aortic-stenosis/symptoms-causes/syc20353139?p=1. Accessed April 17, 2018.

20. Single Ventricle Defects. Boston Children's Hospital Web site. http://www.childrenshospital.org/conditions-and-treatments/conditions/s/singleventricle-defects. Accessed April 17, 2018.

21. Harris I, Lui G. Single Ventricle Defects and the Fontan. Adult Congenital Heart Association. https:/www.achaheart.org/your-heart/health-information/singleventricle-defects-and-the-fontan/. Accessed April 17, 2018.

22. Irving SY. Patterns of weight change in infants with congenital heart disease following neonatal surgery; Potential predictors of growth failure. [dissertation]. University of Pennsylvania; 2011.

23. Medoff-Cooper B, Ravishankar C. Nutrition and growth in congenital heart disease: A challenge in children. Current Opinion in Cardiology. 2013;28(2):122-129. doi: 10.1097/HCO.0b013e32835dd005. 
24. Soliman A, Aggarwal S, Natarajan G. Rehospitalization following neonatal cardiac surgery: Risk factors and outcomes. Amer J Perinatol. 2015;32(12):11331138. doi: 10.1055/s-0035-1549215.

25. Mackie AS, Ionescu-Ittu R, Pilote L, Rahme E, Marelli AJ. Hospital readmissions in children with congenital heart disease: A population-based study. Am Heart J. 2008;155(3):577-584. doi: 10.1016/j.ahj.2007.11.003.

26. Tregay J, Wray J, Bull C, et al. Unexpected deaths and unplanned re-admissions in infants discharged home after cardiac surgery: A systematic review of potential risk factors. Cardiol Young. 2015;25(5):839-852.

27. Saharan S, Legg AT, Armsby LB, Zubair MM, Reed RD, Langley SM. Causes of readmission after operation for congenital heart disease. Ann Thorac Surg. 2014;98(5):1667-1673. doi: 10.1016/j.athoracsur.2014.05.043.

28. Breastfeeding. World Health Organization Web site. http://www.who.int/maternal_child_adolescent/topics/newborn/nutrition/breastfeeding /en/. Accessed May 4, 2018. 
29. Hong BJ, Moffett B, Payne W, Rich S, Ocampo EC, Petit CJ. Impact of postoperative nutrition on weight gain in infants with hypoplastic left heart syndrome. J Thorac Cardiovasc Surg. 2014;147:1319-1325

30. Forchielli ML, McColl R, Walker WA, Lo C. Children with congenital heart disease: A nutrition challenge. Nutr Rev. 1994;52(10):348-353.

31. Anderson JB, Beekman RH, Border WL, et al. Lower weight-for-age z score adversely affects hospital length of stay after the bidirectional glenn procedure in 100 infants with a single ventricle. J Thorac Cardiovasc Surg. 2009;138(2):404. doi: 10.1016/j.jtcvs.2009.02.033.

32. Tandberg BS, Ystrom E, Vollrath ME, Holmstrom H. Feeding infants with CHD with breast milk: Norwegian mother and child cohort study. Acta Pcediatrica. 2010;99(3):373-378. doi: 10.1111/j.1651-2227.2009.01605.x.

33. Torowicz DL, Seelhorst A, Froh EB, Spatz DL. Human milk and breastfeeding outcomes in infants with congenital heart disease. Breastfeeding Medicine. 2015;10(1):31-37. doi: 10.1089/bfm.2014.0059.

34. American Academy of Pediatrics. Breastfeeding and the use of human milk. Pediatrics. 2012;129(3):e841. doi: 10.1542/peds.2011-3552. 
35. Breastfeeding. World Health Organization Web site.

http://www.who.int/nutrition/topics/exclusive_breastfeeding/en/. Accessed April 17, 2018.

36. The American Dietetic Association. Position of the American Dietetic Association: promoting and supporting breastfeeding. J Am Diet Assoc. 2009; 109:1926-1942. doi: 10.1016/j.jada.2009.09.018

37. The American College of Obstetricians and Gynecologists. Optimizing support for breastfeeding as part of obstetric practice. https://www.acog.org/Clinical-Guidanceand-Publications/Committee-Opinions/Committee-on-Obstetric-Practice/OptimizingSupport-for-Breastfeeding-as-Part-of-Obstetric-Practice .Updated February 2016. Accessed April 17, 2018.

38. Breastfeeding a Baby with Congenital Heart Disease. The Children's Hospital of Philadelphia Web site. http://www.chop.edu/pages/breastfeeding-baby-congenitalheart-disease. Accessed April 17, 2018.

39. World Health Organization. Infant and young child feeding: Model chapter for textbooks for medical studies and allied health professionals. http://www.who.int/maternal_child_adolescent/documents/9789241597494/en/. Published 2009. Accessed May 4, 2018. 
40. Labbok M, Krasovec K. Toward consistency in breastfeeding definitions. Stud Fam Plann. 1990;21(4):226-230.

41. Lambert JM, Watters NE. Breastfeeding the infant/child with a cardiac defect: An informal survey. Journal of Human Lactation. 1998;14(2):151-155.

42. Barbas KH, Kelleher DK. Breastfeeding success among infants with congenital heart disease. Pediatr Nurs. 2004;30(4):285.

43. Varan B, Tokel K, Yilmaz G. Malnutrition and growth failure in cyanotic and acyanotic congenital heart disease with and without pulmonary hypertension. Archives of disease in childhood. 1999;81(1):49-52. doi: 10.1136/adc.81.1.49.

44. Mitchell IM, Logan RW, Pollock JC, Jamieson MP. Nutritional status of children with congenital heart disease. Heart. 1995;73(3):277-283.

45. Nydegger A, Walsh A, Penny DJ, Henning R, Bines JE. Changes in resting energy expenditure in children with congenital heart disease. European Journal of Clinical Nutrition. 2009;63(3):392-397. doi: 10.1038/sj.ejcn.1602956. 
46. Ackerman IL, Karn CA, Denne SC, Ensing GJ, Leitch CA. Total but not resting energy expenditure is increased in infants with ventricular septal defects. Pediatrics. 1998;102(5):1172-1177. doi: 10.1542/peds.102.5.1172.

47. Farrell AG, Schamberger MS, Olson IL, Leitch CA. Large left-to-right shunts and congestive heart failure increase total energy expenditure in infants with ventricular septal defect. The American Journal of Cardiology. 2001;87(9):1128-1131. doi: 10.1016/S0002-9149(01)01479-5.

48. Leitch CA, Karn CA, Peppard RJ, et al. Increased energy expenditure in infants with cyanotic congenital heart disease. The Journal of Pediatrics. 1998;133(6):755760. doi: 10.1016/S0022-3476(98)70146-5.

49. Davis D, Davis S, Cotman K, et al. Feeding difficulties and growth delay in children with hypoplastic left heart syndrome versus d-transposition of the great arteries. Pediatr Cardiol. 2008;29(2):328-333. doi: 10.1007/s00246-007-9027-9.

50. Barton JS, Hindmarsh PC, Scrimgeour CM, Rennie MJ, Preece MA. Energy expenditure in congenital heart disease. Arch Dis Child. 1994;70(1):5-9. 
51. Menon G, Poskitt EM. Why does congenital heart disease cause failure to thrive? Arch Dis Child. 1985;60(12):1134-1139.

52. Combs VL, Marino BL. A comparison of growth patterns in breast and bottle-fed infants with congenital heart disease. Pediatr Nurs. 1993;19(2):175-179.

53. Ziegler P, Briefel R, Clusen N, Devaney B. Feeding infants and toddlers study (fits): development of the fits survey in comparison to other dietary survey methods. $J$ Am Diet Assoc. 2006; 106: S12-S27.

54. Breastfeeding Report Card, United States 2018. Centers for Disease Control and Prevention Web site. https://www.cdc.gov/breastfeeding/data/reportcard.htm. Updated August 20, 2018. Accessed February 8, 2019.

55. Costello CL, Gellatly M, Daniel J, Justo RN, Weir K. Growth restriction in infants and young children with congenital heart disease. Congenital Heart Disease. 2015;10(5):447-456. doi: 10.1111/chd.12231.

56. Toole BJ, Toole LE, Kyle UG, Cabrera AG, Orellana RA, Coss-Bu JA. Perioperative nutritional support and malnutrition in infants with congenital heart disease. Congenit. Heart Dis. 2014; 9:15-25. 


\section{Appendix A}

\section{TABLES}

Table 1- Demographic Characteristics of Infants and Parents

\begin{tabular}{|c|c|}
\hline & $\mathbf{N}^{1}(\%)$ \\
\hline \multicolumn{2}{|l|}{ Infant Sex } \\
\hline Male & $55(73 \%)$ \\
\hline Female & $20(27 \%)$ \\
\hline \multicolumn{2}{|l|}{ Infant Ethnicity } \\
\hline Hispanic or Latino & $4(5 \%)$ \\
\hline Non-Hispanic or Latino & $69(95 \%)$ \\
\hline \multicolumn{2}{|l|}{ Infant Race } \\
\hline White or Caucasian & $60(81 \%)$ \\
\hline Black or African American & $8(11 \%)$ \\
\hline Asian or Asian American & $0(0 \%)$ \\
\hline Native Hawaiian or Pacific Islander & $0(0 \%)$ \\
\hline Two or More Races & $5(7 \%)$ \\
\hline Other & $1(1 \%)$ \\
\hline \multicolumn{2}{|l|}{ Maternal Education } \\
\hline 11-12 y of high school & $5(7 \%)$ \\
\hline $1-4$ y of trade school & $1(1 \%)$ \\
\hline $1-4 \mathrm{y}$ of college & $45(61 \%)$ \\
\hline More than $4 \mathrm{y}$ of college & $23(31 \%)$ \\
\hline \multicolumn{2}{|l|}{ Paternal Education } \\
\hline $12 \mathrm{y}$ of high school & $11(15 \%)$ \\
\hline $1-4 \mathrm{y}$ of trade school & $4(6 \%)$ \\
\hline $1-4 \mathrm{y}$ of college & $41(57 \%)$ \\
\hline More than 4 y of college & $16(22 \%)$ \\
\hline Parental Age & Mean \pm SD \\
\hline Maternal Age, y & $30.7 \pm 4.6$ \\
\hline Paternal Age, y & $32.3 \pm 5.4$ \\
\hline $\begin{array}{l}\mathrm{SD}=\text { standard deviation, } \mathrm{y}=\text { years } \\
{ }^{1} \text { Data, for some variables, }<\mathrm{n}=75 \text { due to part }\end{array}$ & ant non-response. \\
\hline
\end{tabular}


Table 2- Infant Medical History at Two Weeks of Age

CHD Primary Diagnosis $\quad$ N (\%)

\begin{tabular}{ll}
\hline HLHS & $34(45 \%)$ \\
\hline TGA-D & $11(15 \%)$ \\
\hline TA & $8(11 \%)$ \\
\hline TOF & $4(5 \%)$ \\
\hline TGA-L & $3(4 \%)$ \\
\hline IAA & $2(3 \%)$ \\
\hline THAA & $2(3 \%)$ \\
\hline DORV & $2(3 \%)$ \\
\hline DILV & $2(3 \%)$ \\
\hline PA & $1(1 \%)$ \\
\hline Single Left Ventricle & $1(1 \%)$ \\
\hline Pulmonary Vein Stenosis & $1(1 \%)$ \\
\hline TAPVR & $1(1 \%)$ \\
\hline Tricuspid Atresia & $1(1 \%)$ \\
\hline Valvular Pulmonary Atresia & $1(1 \%)$ \\
\hline Pulmonary Artery Anomaly & $1(1 \%)$ \\
\hline
\end{tabular}

$\mathrm{CHD}=$ Congenital Heart Disease, HLHS $=$ Hypoplastic left heart syndrome, TGA-D $=$ Transposition of the great arteries-right, $\mathrm{TA}=$ Truncus arteriosus, $\mathrm{TOF}=$ Tetralogy of Fallot, TGA-L= Transposition of the great arteries- left, IAA = Interrupted Aortic Arch, THAA= Tubular hypoplasia of the aortic arch, $\mathrm{DORV}=$ Double outlet right ventricle, DILV $=$ Double inlet left ventricle, $\mathrm{PA}=$ Pulmonary atresia, TAPVR $=$ Total anomalous pulmonary venous return. 
Table 3- Feeding Type and Mode for 0-4 Months of Age, by Month

\begin{tabular}{|c|c|c|c|c|c|}
\hline & $\begin{array}{l}2 \text { weeks } \\
(\mathrm{N}=74)\end{array}$ & $\begin{array}{l}1 \text { Month } \\
(\mathrm{N}=73)\end{array}$ & $\begin{array}{l}2 \text { Months } \\
(\mathrm{N}=72)\end{array}$ & $\begin{array}{l}3 \text { Months } \\
(\mathrm{N}=70)\end{array}$ & $\begin{array}{l}4 \text { Months } \\
(\mathrm{N}=70)\end{array}$ \\
\hline Infant Age, days $($ Mean \pm SD) & $14.2 \pm 4.1$ & $30.4 \pm 6.1$ & $62.5 \pm 7.2$ & $96.7 \pm 12.6$ & $134.8 \pm 48.7$ \\
\hline Type of Feeding & $\mathrm{N}(\%)$ & $\mathrm{N}(\%)$ & $\mathrm{N}(\%)$ & $\mathrm{N}(\%)$ & $\mathrm{N}(\%)$ \\
\hline BM only (predominant) & $61(82 \%)$ & $30(41 \%)$ & $25(35 \%)$ & $25(36 \%)$ & $23(33 \%)$ \\
\hline BM fortified with formula & $0(0 \%)$ & $32(44 \%)$ & $16(22 \%)$ & $13(19 \%)$ & $14(20 \%)$ \\
\hline BM mixed with formula & $10(14 \%)$ & $8(11 \%)$ & $10(14 \%)$ & $12(17 \%)$ & $11(16 \%)$ \\
\hline Formula only (predominant) & $3(4 \%)$ & $3(4 \%)$ & $21(29 \%)$ & $20(28 \%)$ & $22(31 \%)$ \\
\hline $\begin{array}{l}\text { Mix formula/non-infant } \\
\text { formula milk }\end{array}$ & $0(0 \%)$ & $0(0 \%)$ & $0(0 \%)$ & $0(0 \%)$ & $0(0 \%)$ \\
\hline Non-infant formula milk & $0(0 \%)$ & $0(0 \%)$ & $0(0 \%)$ & $0(0 \%)$ & $0(0 \%)$ \\
\hline \multicolumn{6}{|l|}{ Mode of Feeding } \\
\hline Exclusive BF & $0(0 \%)$ & $3(4 \%)$ & $6(8 \%)$ & $3(4 \%)$ & $5(7 \%)$ \\
\hline Mix BF and bottle & $10(14 \%)$ & $15(21 \%)$ & $21(29 \%)$ & $20(29 \%)$ & $14(20 \%)$ \\
\hline Mix BF and tube & $1(1 \%)$ & $2(3 \%)$ & $2(3 \%)$ & $0(0 \%)$ & $1(1 \%)$ \\
\hline Exclusive bottle & $1(1 \%)$ & $16(22 \%)$ & $24(33 \%)$ & $29(41 \%)$ & $31(44 \%)$ \\
\hline Mix bottle and tube & $11(15 \%)$ & $17(23 \%)$ & $10(14 \%)$ & $13(19 \%)$ & $11(16 \%)$ \\
\hline Exclusive tube feeding & $4(5 \%)$ & $6(8 \%)$ & $5(7 \%)$ & $3(4 \%)$ & $6(9 \%)$ \\
\hline Mix BF, bottle, tube & $47(64 \%)$ & $14(19 \%)$ & $4(6 \%)$ & $2(3 \%)$ & $2(3 \%)$ \\
\hline No breast milk or formula & $0(0 \%)$ & $0(0 \%)$ & $0(0 \%)$ & $0(0 \%)$ & $0(0 \%)$ \\
\hline $\begin{array}{l}\mathrm{SD}=\text { standard deviation; } \\
\mathrm{BF}=\text { breastfeed }\end{array}$ & & & & & \\
\hline
\end{tabular}

Table 4- Feeding Type and Mode for 6-12 Months of Age, by Month

\begin{tabular}{|c|c|c|c|c|}
\hline & $\begin{array}{l}6 \text { Months } \\
(\mathrm{N}=70)\end{array}$ & $\begin{array}{l}8 \text { Months } \\
(\mathrm{N}=69)\end{array}$ & $\begin{array}{l}10 \text { Months } \\
(\mathrm{N}=67)^{1}\end{array}$ & $\begin{array}{l}12 \text { Months } \\
(\mathrm{N}=65)^{2}\end{array}$ \\
\hline Infant Age, days (Mean \pm SD) & $187.2 \pm 13.0$ & $246.7 \pm 18.1$ & $300.5 \pm 18.3$ & $375 \pm 17.3$ \\
\hline Type of Feeding & $\mathrm{N}(\%)$ & $\mathrm{N}(\%)$ & $\mathrm{N}(\%)$ & $\mathrm{N}(\%)$ \\
\hline BM only (predominant) & $19(27 \%)$ & $15(22 \%)$ & $17(25 \%)$ & $15(23 \%)$ \\
\hline BM fortified with formula & $9(13 \%)$ & $7(10 \%)$ & $3(5 \%)$ & $2(3 \%)$ \\
\hline BM mixed with formula & $11(16 \%)$ & $8(12 \%)$ & $5(7 \%)$ & $4(6 \%)$ \\
\hline Formula only (predominant) & $31(44 \%)$ & $39(56 \%)$ & $42(63 \%)$ & $35(54 \%)$ \\
\hline Mix formula/ non-infant formula milk & $0(0 \%)$ & $0(0 \%)$ & $0(0 \%)$ & $2(3 \%)$ \\
\hline Non-infant formula milk & $0(0 \%)$ & $0(0 \%)$ & $0(0 \%)$ & $7(11 \%)$ \\
\hline \multicolumn{5}{|l|}{ Mode of Feeding } \\
\hline Exclusive BF & $7(10 \%)$ & $6(9 \%)$ & $5(7 \%)$ & $6(9 \%)$ \\
\hline Mix BF and bottle & $8(11 \%)$ & $5(7 \%)$ & $2(3 \%)$ & $2(3 \%)$ \\
\hline Mix BF and tube & $1(1 \%)$ & $2(3 \%)$ & $2(3 \%)$ & $1(2 \%)$ \\
\hline Exclusive bottle & $36(51 \%)$ & $44(64 \%)$ & $52(78 \%)$ & $47(72 \%)$ \\
\hline Mix bottle and tube & $10(14 \%)$ & $7(10 \%)$ & $2(3 \%)$ & $4(6 \%)$ \\
\hline Exclusive tube feeding & $8(11 \%)$ & $5(7 \%)$ & $4(6 \%)$ & $3(5 \%)$ \\
\hline Mix BF, bottle, tube & $0(0 \%)$ & $0(0 \%)$ & $0(0 \%)$ & $0(0 \%)$ \\
\hline No breast milk or formula & $0(0 \%)$ & $0(0 \%)$ & $0(0 \%)$ & $2(3 \%)$ \\
\hline \multicolumn{5}{|c|}{$\begin{array}{l}\mathrm{SD}=\text { standard deviation; } \mathrm{BF}=\text { breastfeed } \\
{ }^{1} \text { Data is still being collected for the last }(\mathrm{n}=1) \text { participant. }\end{array}$} \\
\hline
\end{tabular}


${ }^{2}$ Data is still being collected for the last three $(n=3)$ participants.

Table 5- Anthropometry for 0-4 Months of Age, by Month

\begin{tabular}{lccccc}
\hline & $\begin{array}{c}\mathbf{2} \text { Weeks } \\
\left(\mathbf{N}^{\mathbf{1}}=\mathbf{6 6}\right)\end{array}$ & $\begin{array}{c}\mathbf{1} \text { Month } \\
\left(\mathbf{N}^{\mathbf{1}=62)}\right.\end{array}$ & $\begin{array}{c}\mathbf{2} \text { Months } \\
\left(\mathbf{N}^{\mathbf{1}}=\mathbf{5 9}\right)\end{array}$ & $\begin{array}{c}\mathbf{3} \text { Months } \\
\left(\mathbf{N}^{\mathbf{1}}=\mathbf{5 6}\right)\end{array}$ & $\begin{array}{c}\mathbf{4} \text { Months } \\
\left(\mathbf{N}^{\mathbf{1}}=\mathbf{5 8}\right)\end{array}$ \\
\hline Infant Age, days (Mean \pm SD) & $14.2 \pm 4.1$ & $30.4 \pm 6.1$ & $62.5 \pm 7.2$ & $96.7 \pm 12.6$ & $134.8 \pm 48.7$ \\
\hline Average Z-Score (Mean \pm SD) & & & & & \\
\hline Weight for Age Z-score & $-0.6 \pm 1.0$ & $-1.0 \pm 1.0$ & $-1.1 \pm 1.0$ & $-1.1 \pm 1.0$ & $-1.1 \pm 0.9$ \\
\hline Length for Age Z-score & $-0.8 \pm 1.1$ & $-0.9 \pm 1.0$ & $-1.1 \pm 1.2$ & $-1.0 \pm 1.2$ & $-0.9 \pm 1.1$ \\
\hline Head Circumference Z-score & $-1.0 \pm 1.1$ & $-1.1 \pm 0.9$ & $-0.9 \pm 1.0$ & $-0.9 \pm 0.9$ & $-0.7 \pm 1.0$ \\
\hline Weight for Length Z-score & $-0.3 \pm 1.0$ & $-0.3 \pm 1.2$ & $-0.1 \pm 1.2$ & $-0.4 \pm 1.2$ & $-0.6 \pm 1.2$ \\
\hline $\begin{array}{l}\mathrm{SD}=\text { standard deviation } \\
{ }^{1} \mathrm{Number} \text { of subjects with at least one Z-score per visit. }\end{array}$ & & & \\
\hline
\end{tabular}

Table 6- Anthropometry for 6-12 Months of Age, by Month

\begin{tabular}{ccccc}
\hline & $\begin{array}{c}\mathbf{6} \text { Months } \\
\left(\mathbf{N}^{\mathbf{1}=65)}\right.\end{array}$ & $\begin{array}{c}\mathbf{8} \text { Months } \\
\left(\mathbf{N}^{\mathbf{1}}=\mathbf{4 7}\right)\end{array}$ & $\begin{array}{c}\mathbf{1 0} \text { Months } \\
\left(\mathbf{N}^{\mathbf{1}}=\mathbf{5 7}\right)\end{array}$ & $\begin{array}{c}\mathbf{1 2} \text { Months } \\
\left(\mathbf{N}^{\mathbf{1}}=\mathbf{6 0}\right)\end{array}$ \\
\hline Infant Age, days (Mean \pm SD) & $187.2 \pm 13.0$ & $246.7 \pm 18.1$ & $300.5 \pm 18.3$ & $375 \pm 17.3$ \\
\hline Average Z-Score (Mean \pm SD) & & & & \\
\hline Weight for Age Z-score & $-0.9 \pm 1.0$ & $-0.8 \pm 1.0$ & $-0.5 \pm 1.0$ & $-0.3 \pm 1.0$ \\
\hline Length for Age Z-score & $-0.8 \pm 1.1$ & $-0.9 \pm 1.1$ & $-0.7 \pm 1.1$ & $-0.5 \pm 1.2$ \\
\hline Head Circumference Z-score & $-0.3 \pm 0.9$ & $-0.1 \pm 0.9$ & $0.0 \pm 1.0$ & $0.1 \pm 0.9$ \\
\hline Weight for Length Z-score & $-0.5 \pm 1.1$ & $-0.3 \pm 1.2$ & $-0.1 \pm 0.9$ & $0.0 \pm 1.0$ \\
\hline
\end{tabular}

Table 7- Cluster Analysis Diet Patterns in the First Year of Life

\begin{tabular}{|l|c|}
\hline & N (\%) \\
\hline Diet Type & \\
\hline BM to Predominantly BM & $26(39.5 \%)$ \\
\hline BM to Mix of BM/Formula & $21(31.8 \%)$ \\
\hline BM to Predominantly Formula & $19(28.7 \%)$ \\
\hline
\end{tabular}


Table 8- Anthropometry Stratified by Diet Pattern for 0-4 Months of Age, by Month

\begin{tabular}{|c|c|c|c|c|c|}
\hline & $\begin{array}{c}2 \text { Weeks } \\
\left(N^{1}=66\right)\end{array}$ & $\begin{array}{l}1 \text { Month } \\
\left(N^{1}=62\right)\end{array}$ & $\begin{array}{c}2 \text { Months } \\
\left(\mathbf{N}^{1}=59\right)\end{array}$ & $\begin{array}{c}3 \text { Months } \\
\left(\mathbf{N}^{1}=56\right)\end{array}$ & $\begin{array}{c}4 \text { Months } \\
\left(N^{1}=58\right)\end{array}$ \\
\hline Infant Age, days $($ Mean \pm SD) & $14.2 \pm 4.1$ & $30.4 \pm 6.1$ & $62.5 \pm 7.2$ & $96.7 \pm 12.6$ & $134.8 \pm 48.7$ \\
\hline \multicolumn{6}{|l|}{$\begin{array}{l}\text { Average Z-Score }(\text { Mean } \pm \text { SE) } \\
\text { BM to Predominantly BM }\end{array}$} \\
\hline Weight for Age Z-score & $-0.3 \pm 0.1$ & $-0.7 \pm 0.1$ & $-0.8 \pm 0.1$ & $-0.8 \pm 0.1$ & $-0.8 \pm 0.2$ \\
\hline Length for Age Z-score & $-0.7 \pm 0.2$ & $-1.0 \pm 0.2$ & $-0.9 \pm 0.2$ & $-0.8 \pm 0.2$ & $-0.7 \pm 0.2$ \\
\hline Head Circumference Z-score & $-1.0 \pm 0.2$ & $-1.0 \pm 0.2$ & $-0.9 \pm 0.2$ & $-0.6 \pm 0.2$ & $-0.5 \pm 0.2$ \\
\hline Weight for Length Z-score & $0.0 \pm 0.2$ & $0.2 \pm 0.2$ & $0.0 \pm 0.2$ & $-0.1 \pm 0.2$ & $-0.3 \pm 0.2$ \\
\hline \multicolumn{6}{|l|}{$\begin{array}{l}\text { Average Z-Score } \\
\text { BM to Mix BM/Formula }\end{array}$} \\
\hline Weight for Age Z-score & $-0.6 \pm 0.2$ & $-1.1 \pm 0.2$ & $-1.2 \pm 0.2$ & $-1.3 \pm 0.2$ & $-1.2 \pm 0.2$ \\
\hline Length for Age Z-score & $-0.6 \pm 0.2$ & $-0.9 \pm 0.2$ & $-0.8 \pm 0.2$ & $-0.9 \pm 0.2$ & $-0.7 \pm 0.2$ \\
\hline Head Circumference Z-score & $-0.9 \pm 0.2$ & $-1.0 \pm 0.2$ & $-0.5 \pm 0.2$ & $-0.6 \pm 0.2$ & $-0.4 \pm 0.2$ \\
\hline Weight for Length Z-score & $-0.4 \pm 0.2$ & $-0.6 \pm 0.2$ & $-0.6 \pm 0.2$ & $-1.0 \pm 0.2$ & $-1.0 \pm 0.2$ \\
\hline \multicolumn{6}{|l|}{$\begin{array}{l}\text { Average Z-Score } \\
\text { BM to Predominantly } \\
\text { Formula } \\
\end{array}$} \\
\hline Weight for Age Z-score & $-0.8 \pm 0.2$ & $-1.1 \pm 0.2$ & $-1.0 \pm 0.2$ & $-1.1 \pm 0.2$ & $-1.0 \pm 0.2$ \\
\hline Length for Age Z-score & $-1.0 \pm 0.2$ & $-0.9 \pm 0.2$ & $-1.4 \pm 0.2$ & $-1.3 \pm 0.2$ & $-1.0 \pm 0.2$ \\
\hline Head Circumference Z-score & $-0.9 \pm 0.2$ & $-1.0 \pm 0.2$ & $-1.2 \pm 0.2$ & $-0.9 \pm 0.2$ & $-0.7 \pm 0.2$ \\
\hline Weight for Length Z-score & $-0.4 \pm 0.2$ & $-0.6 \pm 0.2$ & $0.4 \pm 0.2$ & $0.0 \pm 0.2$ & $-0.3 \pm 0.2$ \\
\hline
\end{tabular}


Table 9- Anthropometry Stratified by Diet Pattern 6-12 Months of Age, by Month

\begin{tabular}{|c|c|c|c|c|}
\hline & $\begin{array}{c}6 \text { Months } \\
\left(N^{1}=65\right)\end{array}$ & $\begin{array}{c}8 \text { Months } \\
\left(\mathrm{N}^{1}=47\right)\end{array}$ & $\begin{array}{c}10 \text { Month } \\
\left(N^{1}=57\right)\end{array}$ & $\begin{array}{c}12 \text { Months } \\
\left(\mathrm{N}^{1}=60\right)\end{array}$ \\
\hline Infant Age, days $($ Mean \pm SD) & $187.2 \pm 13.0$ & $246.7 \pm 18.1$ & $300.5 \pm 18.3$ & $375 \pm 17.3$ \\
\hline \multicolumn{5}{|l|}{$\begin{array}{l}\text { Average Z-Score }\left(\text { Mean }_{ \pm} \mathrm{SE}\right) \\
\text { BM to Predominantly } \mathrm{BM}\end{array}$} \\
\hline Weight for Age Z-score & $-0.6 \pm 0.1$ & $-0.3 \pm 0.2$ & $-0.3 \pm 0.2$ & $-0.1 \pm 0.1$ \\
\hline Length for Age Z-score & $-0.6 \pm 0.2$ & $-0.7 \pm 0.2$ & $-0.7 \pm 0.2$ & $-0.5 \pm 0.2$ \\
\hline Head Circumference Z-score & $-0.4 \pm 0.2$ & $0.3 \pm 0.2$ & $0.1 \pm 0.2$ & $0.1 \pm 0.2$ \\
\hline Weight for Length Z-score & $-0.2 \pm 0.2$ & $0.0 \pm 0.2$ & $0.0 \pm 0.2$ & $0.1 \pm 0.2$ \\
\hline \multicolumn{5}{|l|}{$\begin{array}{l}\text { Average Z-Score } \\
\text { BM to Mix BM/Formula }\end{array}$} \\
\hline Weight for Age Z-score & $-1.2 \pm 0.2$ & $-0.9 \pm 0.2$ & $-0.6 \pm 0.2$ & $-0.3 \pm 0.2$ \\
\hline Length for Age Z-score & $-0.7 \pm 0.2$ & $-0.7 \pm 0.2$ & $-0.5 \pm 0.2$ & $-0.5 \pm 0.2$ \\
\hline Head Circumference Z-score & $-0.2 \pm 0.2$ & $0.2 \pm 0.2$ & $0.0 \pm 0.2$ & $0.2 \pm 0.2$ \\
\hline Weight for Length Z-score & $-1.0 \pm 0.2$ & $-0.6 \pm 0.2$ & $-0.4 \pm 0.2$ & $-0.1 \pm 0.2$ \\
\hline \multicolumn{5}{|l|}{$\begin{array}{l}\text { Average Z-Score } \\
\text { BM to Predominantly Formula }\end{array}$} \\
\hline Weight for Age Z-score & $-0.9 \pm 0.2$ & $-0.8 \pm 0.2$ & $-0.5 \pm 0.2$ & $-0.2 \pm 0.2$ \\
\hline Length for Age Z-score & $-1.1 \pm 0.2$ & $-1.1 \pm 0.2$ & $-0.8 \pm 0.2$ & $-0.3 \pm 0.2$ \\
\hline Head Circumference Z-score & $-0.4 \pm 0.2$ & $0.0 \pm 0.2$ & $0.0 \pm 0.2$ & $0.1 \pm 0.2$ \\
\hline Weight for Length Z-score & $-0.2 \pm 0.2$ & $0.0 \pm 0.2$ & $-0.1 \pm 0.2$ & $0.0 \pm 0.2$ \\
\hline $\begin{array}{l}\mathrm{SD}=\text { standard deviation; } \mathrm{SE}=\text { sta } \\
{ }^{1} \text { Number of subjects with at leas }\end{array}$ & $\begin{array}{l}\text { rd error } \\
\text { e Z-score per }\end{array}$ & isit. & & \\
\hline
\end{tabular}




\section{Appendix B}

\section{FIGURES}

Figure 1: Weight-for-Length Z-scores by Diet Pattern

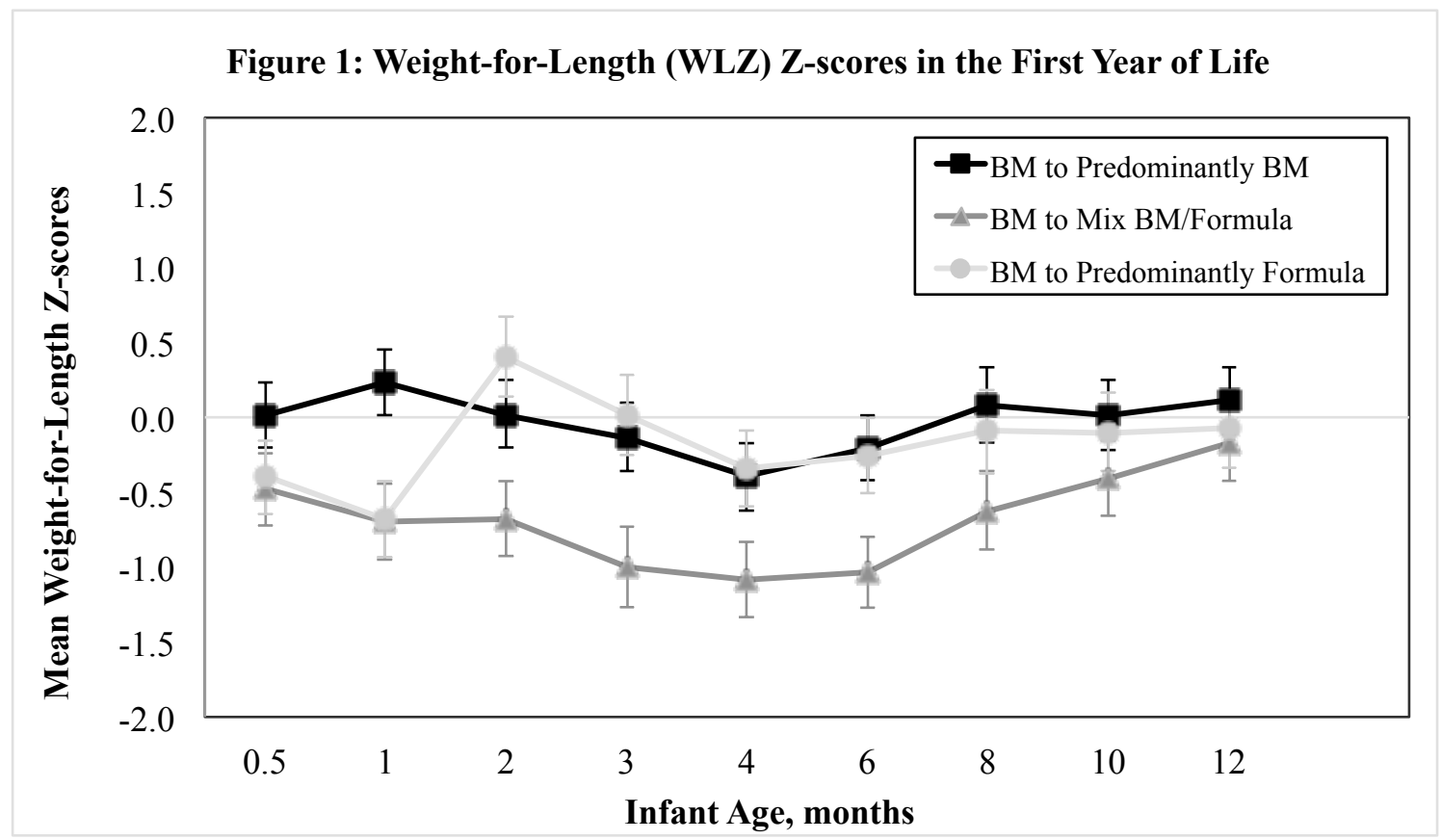


Figure 2: Weight-for-Age Z-scores by Diet Pattern

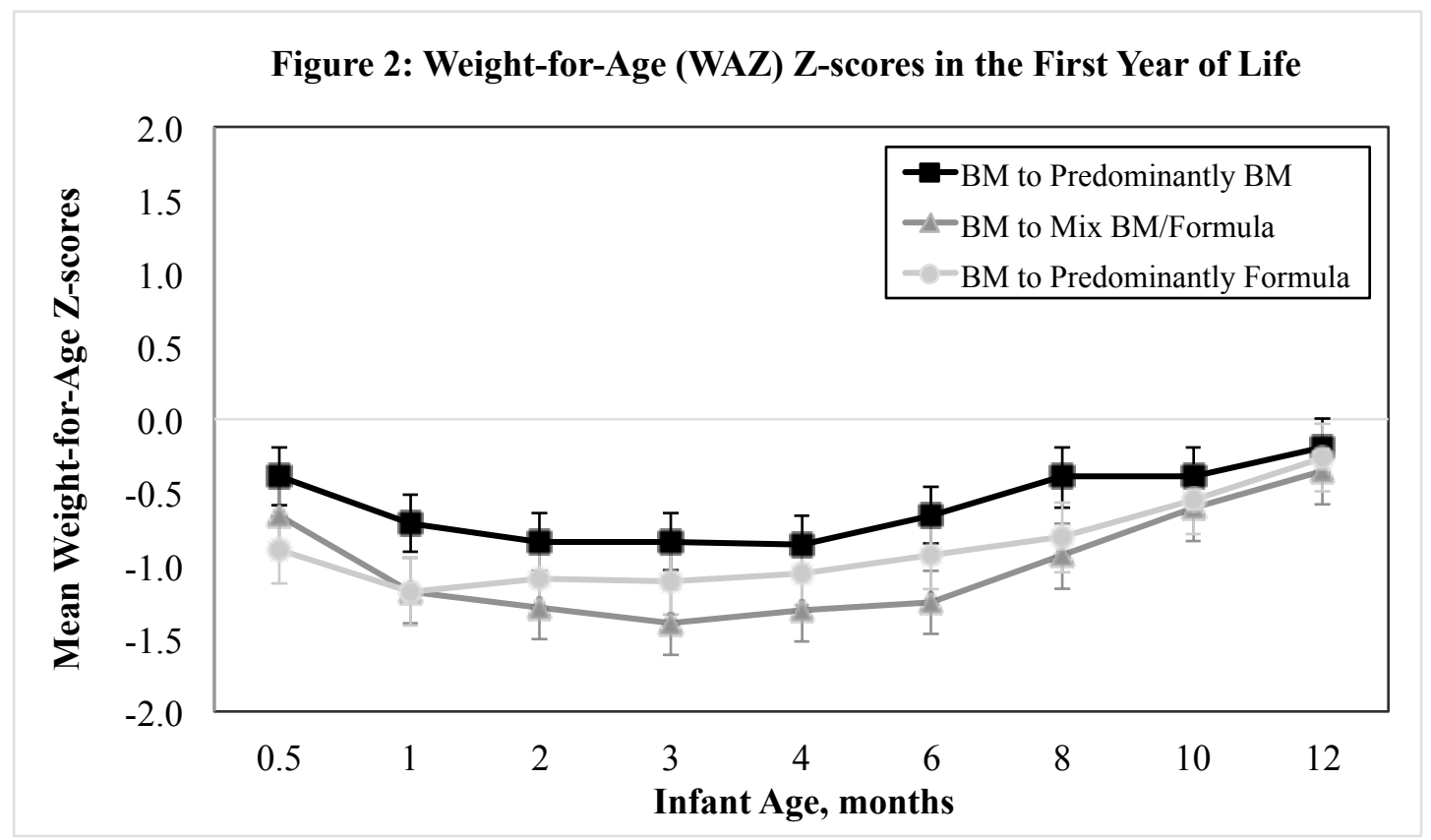


Figure 3: Length-for-Age Z-scores by Diet Pattern

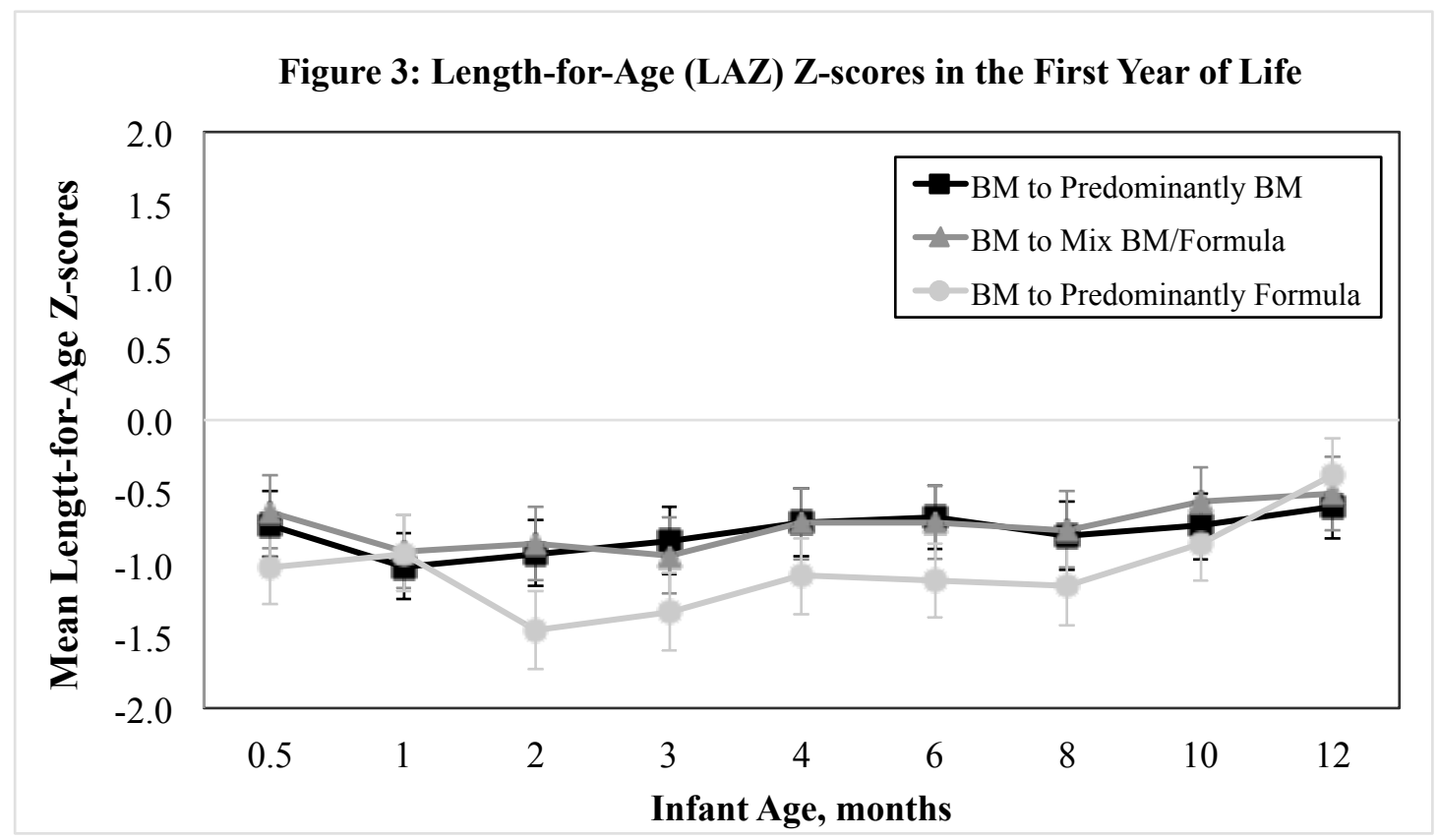


Figure 4: Head Circumference-for-Age Z-scores by Diet Pattern

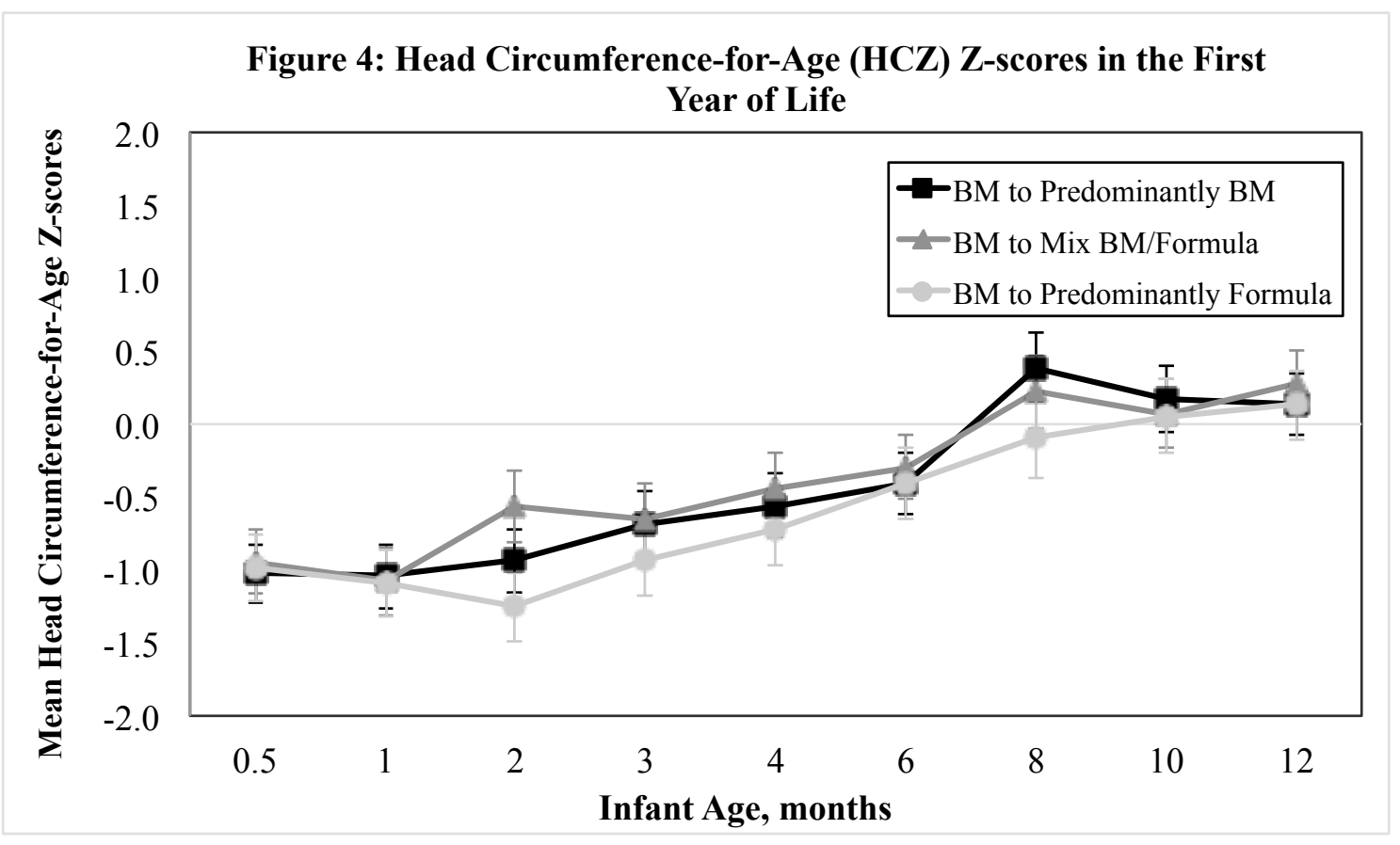


Appendix C

STUDY DOCUMENTS 


\section{C.1. Institutional Review Board Approval Letter}

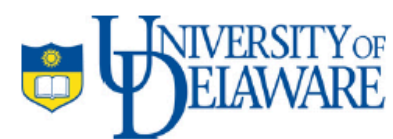

\author{
Research Office
}

210 Hullihen Hall aware Newark, Delaware 19716-1551

Ph: $302 / 831-2136$

Fax: $302 / 831-2828$

DATE:

August 5, 2016

TO:

FROM:

Jillian Trabulsi, PhD

STUDY TITLE:

[813477-2] Breastfeeding in Infants with Congenital Heart Disease

SUBMISSION TYPE:

Amendment/Modification

ACTION

ACKNOWLEDGED

EFFECTIVE DATE:

August 5, 2016

Thank you for submitting the Amendment/Modification materials for the above research study. The University of Delaware IRB has ACKNOWLEDGED your submission. No further action on submission $813477-2$ is required at this time.

The following items are acknowledged in this submission:

- Amendment/Modification - Amendment Form (UPDATED: 08/2/2016)

- Letter - Cover letter (UPDATED: 08/2/2016)

- Training/Certification - RCR certificate (UPDATED: 08/2/2016)

- Training/Certification - Human Subjects training (UPDATED: 08/2/2016)

If you have any questions, please contact Maria Palazuelos at (302) 831-8619 or mariapj@udel.edu Please include your study title and reference number in all correspondence with this office. 


\title{
C.2. Informed Consent Form
}

\author{
다 The Children's Hospital of Philadelphia ${ }^{\circledR}$ \\ Informed Consent Form and HIPAA Authorization \\ Study Title: \\ Version Date: \\ Principal Investigator: \\ Breastfeeding the Infant with Congenital Heart Disease \\ February 12, 2015 \\ Rachelle Lessen, MS, RD, Telephone: 215-590-1089 \\ IBCLC, LDN \\ Emergency Contact: \\ Rachelle Lessen, MS, RD, IBCLC, Telephone: 215-590-1089 \\ LDN
}

\begin{abstract}
You, or your child, may be eligible to take part in a research study. This form gives you important information about the study. It describes the purpose of this research study, and the risks and possible benefits of participating.

If there is anything in this form you do not understand, please ask questions. Please take your time. You do not have to take part in this study if you do not want to. If you take part, you can leave the study at any time.

In the sections that follow, the word "we" means the study principal investigator and other research staff. If you are a parent or legal guardian who is giving permission for a child, please note that the word "you" refers to your child.
\end{abstract}

Why are you being asked to take part in this study?

You are being asked to take part in this research study because you have an infant who was born with a congenital heart defect and you are or plan to breastfeed your infant.

What is the purpose of this research study?

The purpose of this study is to identify factors that affect breastfeeding in infants with congenital heart disease (CHD).

How many people will take part?

About 75 mothers and their infants will take part in this study.

What is involved in the study?

Should you agree to participate in this study, you will be interviewed once a month for the first 4 months of the study either in person or by telephone. After the 4 months, a study team member will contact you once every 2 months until your child is 12 months of age.

How long will you be in this study?

If you agree to take part, your participation will last for 12 months and will involve 9 study visits/telephone contacts. 
What are the study procedures?

The study involves the following procedures.

Interviews: A member of the study team will collect information regarding your background which will include race, ethnicity and education. In addition, you will be asked if you are taking any medications. You will be asked to complete a questionnaire regarding your infant's feeding history and practices as well as medical history. Your infant's weight and length will be obtained from his/her medical record while you are inpatient at CHOP. We will ask about breastfeeding your infant and feeding your infant each month.

When your child is one year of age, we will contact your child's primary care provider to collect information from your child's medical record on growth (weight, length, and head circumference) during their first year of life. Throughout the study you will be asked to report if you think that anything bad has happened as a result of the study.

\section{Visit/Contact Schedule}

The table below provides a brief description of the purpose and duration of each study visit or contact.

\begin{tabular}{|c|c|c|c|}
\hline Visit/contact & Purpose & Main Procedures & Duration \\
\hline $\begin{array}{l}\text { Visit 1, Week 1-2 } \\
\text { or prior to } \\
\text { hospital discharge }\end{array}$ & Screening visit & $\begin{array}{l}\text { Informed Consent, Inclusion Criteria, } \\
\text { Exclusion Criteria, General Interview Form, } \\
\text { Demography, Infant Medical History, Infant } \\
\text { Feeding History, Medications }\end{array}$ & $\begin{array}{l}1 \text { hour and } 30 \\
\text { minutes }\end{array}$ \\
\hline $\begin{array}{l}\text { Contact } 2 \text {, Date } \\
\text { of birth }+30 \text { days }\end{array}$ & Routine Interview & $\begin{array}{l}\text { Monthly Infant Feeding Questionnaire, } \\
\text { Maternal Medications }\end{array}$ & 30 minutes \\
\hline $\begin{array}{l}\text { Contact } 3 \text {, Date } \\
\text { of birth }+60 \text { days }\end{array}$ & Routine Interview & $\begin{array}{l}\text { Monthly Infant Feeding Questionnaire, } \\
\text { Maternal Medications }\end{array}$ & 30 minutes \\
\hline $\begin{array}{l}\text { Contact } 4 \text {, Date } \\
\text { of birth }+90 \text { days }\end{array}$ & Routine Interview & $\begin{array}{l}\text { Monthly Infant Feeding Questionnaire, } \\
\text { Maternal Medications }\end{array}$ & 30 minutes \\
\hline $\begin{array}{l}\text { Contact } 5 \text {, Date } \\
\text { of birth }+120 \\
\text { days }\end{array}$ & Routine Interview & $\begin{array}{l}\text { Monthly Infant Feeding Questionnaire, } \\
\text { Maternal Medications }\end{array}$ & 30 minutes \\
\hline $\begin{array}{l}\text { Contact } 6 \text {, Date } \\
\text { of birth }+180 \\
\text { days }\end{array}$ & Routine Interview & $\begin{array}{l}\text { Monthly Infant Feeding Questionnaire, } \\
\text { Maternal Medications }\end{array}$ & 30 minutes \\
\hline $\begin{array}{l}\text { Contact } 7 \text {, Date } \\
\text { of birth }+240 \\
\text { days }\end{array}$ & Routine Interview & $\begin{array}{l}\text { Monthly Infant Feeding Questionnaire, } \\
\text { Maternal Medications }\end{array}$ & 30 minutes \\
\hline $\begin{array}{l}\text { Contact } 8 \text {, Date } \\
\text { of birth }+300 \\
\text { days }\end{array}$ & Routine Interview & $\begin{array}{l}\text { Monthly Infant Feeding Questionnaire, } \\
\text { Maternal Medications }\end{array}$ & 30 minutes \\
\hline Contact 9, Date & Final Interview & $\begin{array}{l}\text { Monthly Infant Feeding Questionnaire, } \\
\text { Maternal Medications }\end{array}$ & 30 minutes \\
\hline
\end{tabular}

CHOP IRB\#: «ID»)

Effective Date: «ApprovalDate»

Expiration Date: «ExpirationDate»

Page 2 of 6 


\begin{tabular}{|l|l|l|l|}
\hline $\begin{array}{l}\text { of birth }+365 \\
\text { days of age }\end{array}$ & $\begin{array}{l}\text { Growth Data (Weight, length, head } \\
\text { circumference) from your child's first year of } \\
\text { life will be obtained from your primary care } \\
\text { provider }\end{array}$ & \\
\hline
\end{tabular}

What are the risks of this study?

Taking part in a research study involves inconveniences and risks. If you have any questions about any of the possible risks listed below, you should talk to your study doctor or your regular doctor. There is a risk for breach of confidentiality. The study team will make every effort to protect your and your infant's health care information.

\section{Are there any benefits to taking part in this study?}

We cannot guarantee or promise that you will receive any direct benefit by participating in this study. The knowledge gained from this research may help doctors and health care professionals determine how best to support mothers who breastfeed their infant with congenital heart disease.

\section{Do you need to give your consent in order to participate?}

If you decide to participate in this study, you must sign this form. A copy will be given to you to keep as a record. Please consider the study time commitments and responsibilities as a research subject when making your decision about participating in this study

\section{What happens if you decide not to take part in this study?}

Participation in this study is voluntary. You do not have to take part in order to receive care at CHOP.

If you decide not to take part or if you change your mind later there will be no penalties or loss of any benefits to which you are otherwise entitled.

Can you stop your participation in the study early?

You can stop being in the study at any time. You do not have to give a reason.

Can the principal investigator take you out of the study early?

The principal investigator may take you out of the study if:

- The study is stopped.

- You cannot meet all the requirements of the study.

What choices do you have other than this study?

There are options for you other than this study including:

- Not participation in this study.

- You may discuss other options available to you with your doctor. 


\section{What about privacy, authorization for use of Personal Health Information (PHI) and} confidentiality?

As part of this research, health information about you will be collected. This will include information from medical records and interviews. We will do our best to keep your personal information private and confidential. However, we cannot guarantee absolute confidentiality. Your personal information may be disclosed if required by law.

The results of this study may be shown at meetings and published in journals to inform other doctors and health professionals. We will keep your identity private in any publication or presentation.

Several people and organizations may review or receive your identifiable information. They will need this information to conduct the research, to assure the quality of the data, or to analyze the data or samples. These groups include:

- Members of the research team and other authorized staff at CHOP;

- People from agencies and organizations that perform independent accreditation and/or oversight of research; such as the Department of Health and Human Services, Office for Human Research Protections.

By law, $\mathrm{CHOP}$ is required to protect your health information. The research staff will only allow access to your health information to the groups listed above. By signing this document, you are authorizing CHOP to use and/or release your health information for this research. Some of the organizations listed above may not be required to protect your information under Federal privacy laws. If permitted by law, they may be allowed to share it with others without your permission.

The identifiable information from this study will be destroyed 7 years after the study is completed. Your permission to use and share the information and data from this study will continue until the research study ends and will not expire. Researchers continue to analyze data for many years and it is not possible to know when they will be completely done.

\section{Can you change your mind about the use of personal information?}

You may change your mind and withdraw your permission to use and disclose your health information at any time. To take back your permission, you must tell the investigator in writing.

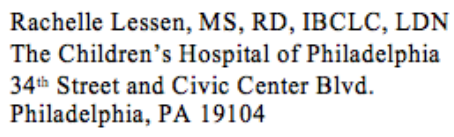

In the letter, state that you changed your mind and do not want any more of your health information collected. The personal information that has been collected already will be used if necessary for the research. No new information will be collected. If you withdraw your permission to use your personal health information, you will be withdrawn from the study

\section{Additional Information}

You will be informed if changes to the study are needed to protect your health. You will be told about any new information that could affect your willingness to stay in the study, such as new risks, benefits or alternative treatments.

CHOP IRB\#: «ID» 


\section{Financial Information}

While you are in this study, the cost of your usual medical care - procedures, medications and doctor visits - will continue to be billed to you or your insurance.

Will there be any additional costs?

There are no additional costs for participating in this study.

Will you be paid for taking part in this study?

You will not receive any payments for taking part in this study.

Who is funding this research study?

The Division of Nursing at The Children's Hospital of Philadelphia is funding this research.

\section{What if you have questions about the study?}

If you have questions about the study, call the principal investigator, at 215-590-1089. You may also talk to your own doctor if you have questions or concerns.

The Institutional Review Board (IRB) at The Children's Hospital of Philadelphia has reviewed and approved this study. The IRB looks at research studies like these and makes sure research subjects' rights and welfare are protected. If you have questions about your rights or if you have a complaint, you can call the IRB Office at 215-590-2830.

A description of this clinical trial will be available on http://www.ClinicalTrials.gov, as required by U.S. Law. This Web site will not include information that can identify you. At most, the Web site will include a summary of the results. You can search this Web site at any time.

CHOP IRB\#: «ID» 
Consent to Take Part in this Research Study and Authorization to Use and Disclose Health Information for the Research

The research study and consent form have been explained to you by:

By signing this form, you are indicating that you have had your questions answered, you agree to take part in this research study and you are legally authorized to consent to your child's participation and your participation. This study involves both the mother and the child. By signing this form you are consenting for both your participation as well as the participation of your child. You are also agreeing to let CHOP use and share your child's health information as explained above. If you don't agree to the collection, use and sharing of your child's health information, your child cannot participate in this study. NOTE: $A$ foster \$ parent is not legally authorized to consent for a foster child's participation.

Name of Subject (child)

Signature of Mother (18 years or older)

Name of Authorized Representative to

consent for child

Signature of Authorized Representative

(Mother)
Name of Subject (Mother)

Date

Relation to subject:

$\square$ Mother

Date

CHOP IRB\#: «ID»

Effective Date: «ApprovalDate»

Expiration Date: «ExpirationDate» 


\section{C.3. Inclusion/Exclusion Criteria Form \\ Inclusion/Exclusion Criteria}

Principal Investigator: Rachelle Lessen, MS, RD, IBCLC

Title: Breastfeeding in infants with Congenital Heart Disease

Subject No.

Visit Date:_______

Inclusion Criteria:

\begin{tabular}{|c|c|c|c|c|}
\hline Infant is $\geq 37$ and $\leq 42$ week gestation at birth & & Yes & & No \\
\hline Infant is a singleton & 믄 & Yes & 믄 & No \\
\hline Infant is appropriate for gestational age & $\square$ & Yes & $\square$ & No \\
\hline Infant has been diagnosed with congenital heart disease & $\square$ & Yes & $\square$ & No \\
\hline $\begin{array}{l}\text { Infant has undergone or will undergo neonatal corrective or palliative surgery prior } \\
\text { to discharge }\end{array}$ & $\square$ & Yes & $\square$ & No \\
\hline Mother is $\geq 18$ years of age & $\square$ & Yes & $\square$ & No \\
\hline Mother is English speaking & $\square$ & Yes & $\bar{\square}$ & No \\
\hline Mother intents to breastfeed & & Yes & $\square$ & No \\
\hline
\end{tabular}

Exclusion Criteria:

Infant does not have any other known anomalies which are known to affect feeding (cleft palate, craniofacial deformities, inborn errors of metabolism, etc.)

$\square$ Yes $\square$ No True False 


\section{C.4. General Interview Questionnaire}

\section{General Interview Form: Visit 1}

Principal Investigator: Rachelle Lessen, MS, RD, IBCLC, Jillian Trabulsi, PhD RD

Co-investigators: Chelsea Hollowell, Samantha Elliott

Title: Breastfeeding in infants with Congenital Heart Disease

Subject No.

Visit Date:

GENERAL INTERVIEW FORM- VISIT 1

Interviewer Initials:

I will be asking you a number of questions about yourself and your child. Some of the questions may seem fairly personal, so l'd like you to keep in mind that we administer the same questionnaire to every subject in this study, all of the information is relevant to the research we are doing, and everything you tell me is strictly confidential.

QUESTIONS ABOUT MOM

1. What is your (Mom's) date of birth?

Age:

2. Are you single, divorced, widowed, or married?

3. What is the date of birth of the child to be enrolled?

4. What is the gender of the child to be enrolled in this study?

5. How many children do you have?

6. What is the age and gender of your other children? age

age___ gender of $\vec{\delta}$

age__ gender 우 $\delta$

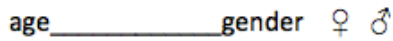

age___ gender $q \delta$

age__ gender $q \delta$

8. What is the birth order of the child currently enrolled in the study?

9. Please list the relation and ages of EVERYONE, including yourself, other adults and other children, PRESENTLY LIVING IN YOUR HOME. (Do not use names, only their relation to you (i.e. mother, father, husband, son, daughter, etc.)

RELATION:

Self

AGE:

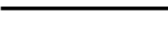

SMOKER? (Yes / No) 


\section{General Interview Form: Visit 1}

Principal Investigator: Rachelle Lessen, MS, RD, IBCLC, Jillian Trabulsi, PhD RD

Co-investigators: Chelsea Hollowell, Samantha Elliott

Title: Breastfeeding in infants with Congenital Heart Disease

Subject No._----

Visit Date:___

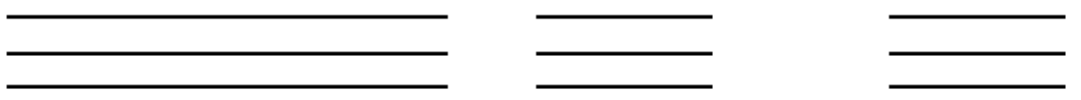

10. Your (Mom's) height:

ft.

in.

Your (Mom's) weight: lbs.

QUESTIONS ABOUT THE CHILD'S FATHER

11. How old is your child's father? How tall is he? How much does he weigh?

12. What is the best method to contact you for study updates, reminders, scheduling, etc.? Please provide all information, and check which you prefer:

- Telephone contact information

- Home

Cell

a Work

Which do you prefer for contact

o Home

- Cell Phone

amail: 


\section{C.5. Demography Questionnaire}

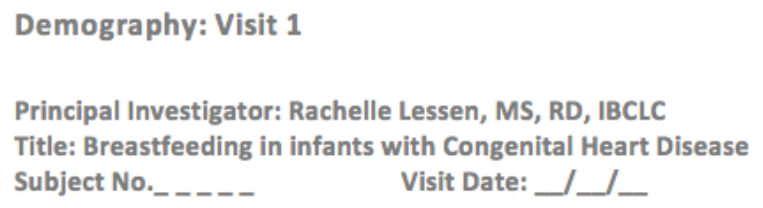

DEMOGRAPHIC QUESTIONNAIRE

\section{QUESTIONS ABOUT MOM}

How many years of schooling have you had? (Circle the last grade completed.)

$\begin{array}{lcccccccc}\text { Grade School: } & 1 & 2 & 3 & 4 & 5 & 6 & 7 & 8 \\ \text { High School: } & 9 & 10 & 11 & 12 & & & & \\ \text { Trade School: } & 1 & 2 & 3 & 4 & & & & \end{array}$

If a trade school, how long was the program in years or months?

College/University: $\quad \begin{array}{lllll}1 & 2 & 3 & 4 & \text { (Name of college: }\end{array}$

Graduate education (Master's or Doctoral Degree):

Do you have a job in addition to being a mother? YES NO

If yes, what kind of work do you do?

\section{QUESTIONS ABOUT THE CHILD'S FATHER}

How many years of schooling has your child's father had? (Circle the last grade completed.)

$\begin{array}{lcccccccc}\text { Grade School: } & 1 & 2 & 3 & 4 & 5 & 6 & 7 & 8 \\ \text { High School: } & 9 & 10 & 11 & 12 & & & & \\ \text { Trade School: } & 1 & 2 & 3 & 4 & & & & \end{array}$

- If a trade school, how long was the program in years or months?

College: $123 \quad 34$ (Name of college:

Graduate education (Master's or Doctoral degree):

What is your child's father's occupation?

|

Do you currently participate in federal nutrition education programs such as WIC? Yes

If so, but it is not WIC, please specify the name: 
Demography: Visit 1

Principal Investigator: Rachelle Lessen, MS, RD, IBCLC

Title: Breastfeeding in infants with Congenital Heart Disease

Subject No.

Visit Date: ___

If not participating presently, have you participated in the past?

Yes

No

If yes, when did you participate (dates)?

What is YouR (Mother) ethnic category?

a Hispanic or Latino

a Not Hispanic or Latino

What is YoUR (Mother) racial background? (Check all that apply)

a White or Caucasian

a Black or African American

a American Indian or Alaskan Native

a Asian or Asian American

a Native Hawaiian or Pacific Islander

व Other (please specify)

What is YOUR CHILD'S FATHER'S ethnic category?

a Hispanic or Latino

a Not Hispanic or Latino

What is YOUR CHILD'S FATHER'S racial background? (Check all that apply)

व White or Caucasian

a Black or African American

- American Indian or Alaskan Native

- Asian or Asian American

a Native Hawaiian or Pacific Islander

व Other (please specify)

What is YOUR CHILD'S ethnic category?

a Hispanic or Latino

a Not Hispanic or Latino 


\section{C.6. Infant Medical History Questionnaire}

\section{Infant Medical History- Visit 1}

Principal Investigator: Rachelle Lessen, MS, RD, IBCLC

Title: Breastfeeding in infants with Congenital Heart Disease

Subject No._- - - -

Visit Date: ___ _

1. What was your infant's congenital heart disease diagnosis?

$\square$ Hypoplastic left heart syndrome

$\square$ L-Transposition of great arteries

$\square$ Double outlet right ventricle

$\square$ Total anomalous pulmonary venous return

$\square$ AP Window $\square$ Valvular pulmonary atresia

$\square$ D-transposition of great arteries

$\square$ Interrupted aortic arch

$\square$ Truncus arteriosus

$\square$ Other: $\square$ Double inlet left ventricle

$\square$ Tetralogy of fallot

$\square$ Coarctation of the aorta

$\square$ Valvular septal defect

2. What was your infant's gestational age? weeks

3. What was your infant's birth weight? $\mathrm{kg}$

4. What was your infant's birth length? $\mathrm{cm}$

5. What is your infant's medical history? (other diagnoses besides congenital heart disease)

6. What is your infant's surgical history?

Describe:

Date:

Describe:

Date:

Describe:

pate: 


\section{C.7. Infant Feeding History: Visit 1 at 2 Weeks Questionnaire \\ Infant Feeding History: Visit 1 at 2 weeks}

Principal Investigator: Rachelle Lessen, MS, RD, IBCLC

Title: Breastfeeding in infants with Congenital Heart Disease

Subject No.

Visit Date:____

This form is to be completed when subject is enrolled or prior to discharge

FEEDING INFORMATION

1. Has your child ever been breastfed? Yes No

If NO skip to question \#2

About how long after delivery did you breast feed or try to breastfeed your baby for the very first time?

․ Within first hour

ㅁ 1-12 hours

ㄱ 12-24 hours

a 24-36 hours

a 48-72 hours

$\square>72$ hours

Where did you first breastfeed?

口 SDU

$\square \mathrm{CICU}$

ㅁirth hospital

$\square$ Other

Was your infant breastfed prior to his/her first cardiac surgery? Yes

No

Was your infant breastfed successfully after his/her first cardiac surgery? Yes

No

While in the hospital did/has anyone helped you with breastfeeding by showing you how or talking to you about breastfeeding? Yes

No

Who helped you with breastfeeding? (Check all that apply)

$\square$ Doctor

$\square$ Lactation Consultant

Friend(s)

$\square$ Midwife

ㅁ Nurse

ㄱamily Member(s)

O Other:

Using 1 to mean "Not at all helpful" and $\mathbf{5}$ to mean "Very helpful", how helpful was the breastfeeding help you received from a doctor, midwife, nurse or lactation consultant?

1

2

3 


\section{Infant Feeding History: Visit 1 at $\mathbf{2}$ weeks}

Principal Investigator: Rachelle Lessen, MS, RD, IBCLC

Title: Breastfeeding in infants with Congenital Heart Disease

Subject No.

Visit Date:____

Using 1 to mean "Disliked Very Much" and $\mathbf{5}$ to mean "Liked very much" how would you say you felt about breastfeeding during the first week you were breastfeeding?

1

2

3

4

5

Has your infant ever been test weighed to determine volume of milk consumed? Yes

If so: Date: Volume: Location: Hospital Other:

Did you have any pain while breastfeeding at any time in the first $\mathbf{2}$ weeks? Yes

Did you have any of the following problems breastfeeding your baby during your first 2 weeks of breastfeeding?

․ My baby had trouble sucking

․ My baby had trouble latching on

․ I didn't have enough milk

My baby choked

․ My nipples were sore, cracked, or bleeding

$\square \quad$ My baby wouldn't wake up to nurse regularly enough

$\square \quad$ My breasts were overfull (engorged)

$\square$ My baby was not interest in nursing

ㄱ I had a yeast infection of the breast

․ My baby got distracted a I had a clogged milk duct

प My baby nursed too often

$\square$ My breasts were infected or abscessed

口 It took too long for my milk to come in

ㅁ My breasts leaked too much

a I had trouble getting the milk flow to start

ㅁ I had some other problem

․ My baby didn't gain enough weight

․ My babylost too much weight

ㄱ I had no problems

2. Were you ever able to hold your infant skin to skin?

If so, how old was your infant? days

3. How long did it take for your milk to come in?

$\square \quad 1$ day or less $\square \quad 2$ days $\square 3$ days

ㄴ 4 days

More than 4 days 


\section{Infant Feeding History: Visit $\mathbf{1}$ at $\mathbf{2}$ weeks}

Principal Investigator: Rachelle Lessen, MS, RD, IBCLC, Jillian Trabulsi, PhD RD

Co-investigators: Chelsea Hollowell, Samantha Elliott

Title: Breastfeeding in infants with Congenital Heart Disease

Subject No.

Visit Date:____

4. Has your child ever been formula fed? Yes No

How old was your baby when he or she was first fed formula?

ㅁ 1 day or less

(ㄴ) 2-6 days

口 7-13 days

口 14-20 days

- More than 20 days

$\square \quad$ Never fed formula

Name of formula(s)

5. Have you previously breastfed with your other children? Yes

No

6. Has your child ever received donor milk? Yes No

How old was baby when donor milk was started?

$\square \quad 1$ day or less $\square \quad$ 2-6 days $\square \quad 7-13$ days

How many days did baby receive donor milk?

$\square \quad 1$ day $\square \quad 2$-4 days $\square \quad 5-7$ days $\square>7$ days

7. Has your baby ever received a bottle? Yes No

How old was your baby when a bottle was first introduced?
$\square$ Within first hour
口 1-12 hours
( $12-24$ hours
a 24-36 hours
( $\quad 48-72$ hours
$\square>72$ hours

8. Was your baby ever tube fed? Yes No

How old was the baby when the tube was first introduced?

9. How soon after birth did you first pump for your baby?
$\square \quad 0-6$ hours
ㅁ 6-12 hours
ㅁ 12-24 hours
24-48 hours
$>48$ hours

What pump(s) did you use while your baby was in the hospital? 


\section{C.8. Monthly Infant Feeding Questionnaire- In Hospital \\ Monthly Infant Feeding Questionnaire - In hospital}

Principal Investigator: Rachelle Lessen, MS, RD, IBCLC

Title: Breastfeeding in infants with Congenital Heart Disease

Subject No.

Visit Date:______

FEEDING INFORMATION

1. What is your baby currently feeding?

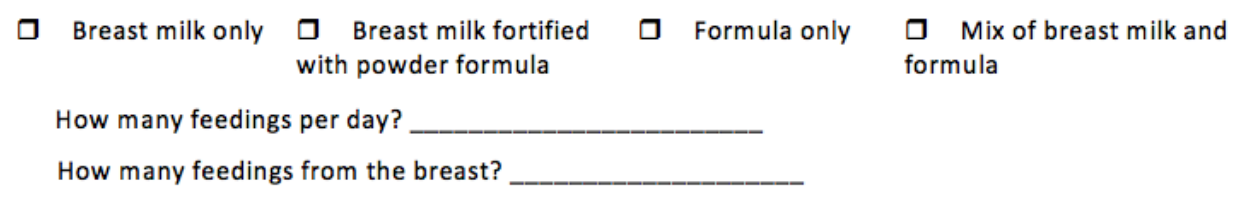

If not breastfeeding or feeding your breast milk: Skip to question \# 9

2. About how long does an average breastfeeding last?
ㅁ Less than 10 minutes
민 20 minutes
ㄴ 40-49 minutes
ㅁ 10-19 minutes
30-39 minutes
ㄷ $50+$ minutes

3. In an average 24-hour period, what is the LONGEST time for you, the mother, between breastfeeding or expressing milk? Please consider both day and night time and begin the count from the start of one breastfeeding/expressing session to the start of the next.

$$
\text { Hours AND }
$$
Minutes

4. Are you currently receiving help with breastfeeding? Yes

If so, from whom:

$\square$ Nurse $\square$ Lactation Consultant $\square$ Other:

5. Has your infant been test weighed to determine volume of milk consumed? Yes

If so: Date(s): Volume:

6. Are you currently feeding your infant a bottle?

Yes

No

How many feedings per day from the bottle? 


\section{Monthly Infant Feeding Questionnaire - In hospital}

Principal Investigator: Rachelle Lessen, MS, RD, IBCLC

Title: Breastfeeding in infants with Congenital Heart Disease

Subject No.

Visit Date: ___

7. Are you currently feeding expressed breast milk in a bottle? Yes

No

1. If yes, is it fortified? concentration

2. If yes, how much per feeding?

3. If yes, how often per day?

4. If yes, how many oz per day?

8. Are you currently pumping? Yes No

If so, how many times per day?

Daily milk production

Which pump are you using?

If you are no longer pumping, when and why did you stop?

9. Are you currently using donor milk? Yes

No Obtained from

10. Are you currently using formula? Yes

No

If yes, name of formula?

If yes, how much per feeding?

If yes, how often per day?

If yes, how many oz per day? -

Concentration

11. If bottle feeding, how long does an average bottle feeding last?
$\square \quad$ Less than 10 minutes
ㅁ-29 minutes
ㄴ 40-49 minutes
ㅁ 10-19 minutes

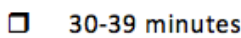
$\square \quad 50+$ minutes

12. Has your infant been fed via a nasogastric tube over the past month? Yes No What percentage of feedings are via NG? 


\section{C.9. Monthly Infant Feeding Questionnaire- First Home Contact \\ Monthly Infant Feeding Questionnaire - First home contact}

Principal Investigator: Rachelle Lessen, MS, RD, IBCLC

Title: Breastfeeding in infants with Congenital Heart Disease

Subject No.

Visit Date: ___ _

\section{FEEDING INFORMATION}

1. When you left the hospital what were you feeding your baby?
$\square$ Breast milk only
$\square$ Breast milk fortified with powder formula
Formula only
$\square$ Mix of breast milk and formula

a. Was your breast milk fortified at time of discharge? With what formula?

b. Calorie concentration

2. When you left the hospital how were you feeding your baby?

$\begin{array}{lll}\square \text { Breastfeeding only } & \square \text { Breastfeeding and bottle } & \square \text { Breastfeeding and tube feeding } \\ & \text { feeding } & \\ \begin{array}{l}\square \text { Bottle feeding and tube } \\ \text { feeding }\end{array} & \square \text { Tube feeding only } & \begin{array}{l}\square \text { Breastfeeding, bottle feeding } \\ \text { and tube feeding }\end{array}\end{array}$

3. Was your infant breastfed successfully before hospital discharge? Yes No

4. Were you given any information about breastfeeding support groups or services before you went home from the hospital? Yes No

5. What was your daily production at the time of discharge?
口 $<250 \mathrm{ml} / \mathrm{day}$
$250-500 \mathrm{ml} /$ day
ㄱ $\quad 500-750 \mathrm{ml} / \mathrm{day}$
$\square>750 \mathrm{ml} /$ day

6. What was your peak daily milk production?
口 $<250 \mathrm{ml} / \mathrm{day}$
$\quad 250-500 \mathrm{ml} / \mathrm{day}$
口 $\quad 500-750 \mathrm{ml} / \mathrm{day}$
$\square>750 \mathrm{ml} /$ day

When was this?
ㅁ Week 1
Week 2
ㄴ Week 3
Week 4

7. What is your baby currently feeding?

$\square$ Breast milk only $\square$ Breast milk fortified with powder formula

Formula only

$\square$ Mix of breast milk and per day?

How many feedings per day?

How many feedings from the breast? 


\section{Monthly Infant Feeding Questionnaire - First home contact}

Principal Investigator: Rachelle Lessen, MS, RD, IBCLC

Title: Breastfeeding in infants with Congenital Heart Disease

Subject No.

Visit Date:____

If not breastfeeding or feeding your breast milk: Skip to question \# 15

8. About how long does an average breastfeeding last?
ㄴ Less than 10 minutes
ㄱ 20-29 minutes
$\quad$ 40-49 minutes
ㅁ 10-19 minutes
구일
$50+$ minutes

9. In an average $\mathbf{2 4}$ hour period, what is the LONGEST time for you, the mother, between breastfeedings or expressing milk? Please consider both day and night time and begin the count from the start of one breastfeeding/expressing session to the start of the next.

Hours AND Minutes

10. Are you currently receiving help with breastfeeding? Yes

No

If so, from whom:
$\square$ Breastfeeding Support Group
Breastfeeding Class
ㄴ Lactation Consultant
Other:

11. Has your infant been test weighed to determine volume of milk consumed? Yes

If so: Date(s): Volume:

Location: Home Hospital Other:

12. Are you currently feeding your infant a bottle? Yes

No How many feedings per day from the bottle?

13. Are you currently feeding expressed breast milk in a bottle? Yes No

1. If yes, is it fortified? concentration

2. If yes, how much per feeding?

3. If yes, how often per day?

4. If yes, how many oz per day? -

14. Are you currently pumping? Yes No

If yes, how many times per day?

Daily milk production

Which pump are you using?

If you are no longer pumping, when and why did you stop? 


\section{Monthly Infant Feeding Questionnaire - First home contact}

Principal Investigator: Rachelle Lessen, MS, RD, IBCLC

Title: Breastfeeding in infants with Congenital Heart Disease

Subject No.

Visit Date:___

15. Are you currently using donor milk? Yes

No Obtained from

16. Are you currently using formula? Yes

No

If yes, name of formula?

If yes, how much per feeding?

If yes, how often per day?

If yes, how many oz per day? -

Concentration

17. If bottle feeding how long does an average bottle feeding last?
․ Less than 10 minutes
ㄱ 20-29 minutes
ㄴ 40-49 minutes
ㅁ 10-19 minutes

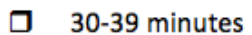

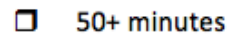

18. If formula fed, how do you prepare your infant's formula?

Amount of powder___ scoops
Amount of water ___ oz or cups (please circle one)
Do you add anything to your baby's bottle? Yes
If Yes, what?
How much?
How often?

19. In the past month, has your infant been hospitalized for any reason or has your baby been taken to a hospital for any outpatient procedure or surgery? Yes

How many nights was your baby in the hospital for the most recent problem since discharge after birth? Nights

20. Has your infant been fed via a nasogastric tube over the past month?

Yes

No

What percentage of feeds are via the NG tube? 


\section{C.10. Monthly Infant Feeding Questionnaire- All Other Home Contacts}

\section{Monthly Infant Feeding Questionnaire - all other home}

\section{contacts}

Principal Investigator: Rachelle Lessen, MS, RD, IBCLC

Title: Breastfeeding in infants with Congenital Heart Disease

Subject No.

Visit Date: ____

\section{FEEDING INFORMATION}

1. What is your baby currently feeding?
ㅁ Breast milk only$$
\text { a Breast milk fortified }
$$ with powder formula
다mula only
ㅁ Mix of breast milk and formula

How many feedings per day?
How many feedings from the breast?

If not breastfeeding or feeding your breast milk: Skip to question \# 9

2. About how long does an average breastfeeding last?
a Less than 10 minutes
ㄱ 20-29 minutes
a 40-49 minutes
ㄱ 10-19 minutes
ㄱ $30-39$ minutes
두 minutes

3. In an average 24 hour period, what is the LONGEST time for you, the mother, between breastfeedings or expressing milk? Please consider both day and night time and begin the count from the start of one breastfeeding/expressing session to the start of the next.
Hours
AND Minutes

4. Are you currently receiving help with breastfeeding? Yes

No
If so, from whom:
Breastfeeding Support Group
Breastfeeding Class
Lactation Consultant

Other: 


\section{Monthly Infant Feeding Questionnaire - all other home contacts}

Principal Investigator: Rachelle Lessen, MS, RD, IBCLC

Title: Breastfeeding in infants with Congenital Heart Disease

Subject No.

$---$

Visit Date: _____

5. Has your infant been test weighed to determine volume of breastmilk consumed? Yes If so: Date(s): Volume:

6. Are you currently feeding your infant a bottle?

How many feedings per day from the bottle?

7. Are you currently feeding expressed breast milk in a bottle? Yes

No

If yes, is it fortified? concentration

If yes, how much per feeding?

If yes, how often per day?

If yes, how many oz per day?

8. Are you currently pumping? Yes No

If so, how many times per day?

Daily milk production

Which pump are you using?

If you are no longer pumping, when and why did you stop?

9. Are you currently using donor milk?

Yes

No

Obtained from

10. Are you currently using formula? Yes

No

If yes, name of formula?

If yes, how much per feeding?

If yes, how often per day?

If yes, how many oz per day?

Concentration 
Monthly Infant Feeding Questionnaire - all other home contacts

Principal Investigator: Rachelle Lessen, MS, RD, IBCLC

Title: Breastfeeding in infants with Congenital Heart Disease

Subject No._-_--

Visit Date:

11. If bottle feeding how long does an average bottle feeding last?
$\square \quad$ Less than 10 minutes
ㄱ 20-29 minutes
a 40-49 minutes
ㅁ 10-19 minutes
기 $\quad 30-39$ minutes
다 minutes

12. If formula feeding, how do you prepare your infant's formula?

Amount of powder scoops

Amount of water oz or cups (please circle one)

Do you add anything else to your baby's bottle? Yes If Yes, what? Yes No How much? How often?

13. In the past month, has your infant been hospitalized for any reason or has your baby been taken to a hospital for any outpatient procedure or surgery? Yes

How many nights was your baby in the hospital for the most recent problem since discharge after birth? Nights

What percentage of feedings are via NG?

15. Has your child received any solid foods? Yes No 
